The Journal of the Learning Sciences. Vol 10 N 4. NJ: Lawrence Erlbaum. Pp 365-415

\title{
Identity construction environments: developing personal and moral values through the design of a virtual city
}

\author{
Marina Umaschi Bers \\ MIT Media Laboratory \\ 20 Ames St., Room E15-320A \\ Cambridge, MA 02139 USA \\ 617-253-0379 \\ 617-253-6215 [fax] \\ marinau@media.mit.edu
}


The Journal of the Learning Sciences. Vol 10 N 4. NJ: Lawrence Erlbaum. Pp 365-415

\section{Abstract}

We live in a society where concepts of self, community and "what is right and wrong" are constantly changing. This makes it particularly challenging for young people to construct a sense of self and to identify their most cherished values. Therefore, there is an amounting pressure in schools and society to create learning environments to explore these issues. Two research questions are at the heart of the work presented in this paper: What kind of learning environment will afford opportunities for young people to naturally engage in reflection and discussion about issues of identity, in particular personal and moral values? And, how can technologies have an impact on character and moral education? I propose identity construction environments as technological tools purposefully designed with the goal of supporting young people in the exploration of these issues.

I first describe the design principles that distinguish these environments from other learning technologies. I also specify the learning experiences they do afford_ namely the understanding of identity as a complex construction composed by different elements, including personal and moral values. Then I present the conceptual foundations and implementation of the Zora identity construction environment. Zora is a 3D multi-user virtual environment that engages learners in the design of a graphical virtual city and its social organization. I describe a summer workshop conducted with a multi-cultural group of teenagers using Zora. They designed a virtual city populated with objects and characters representing aspects of themselves and their values. In this participatory micro-community those values were put to test. Finally I conclude with reflections and future work that points towards a new research agenda in the area of the learning sciences. 
The Journal of the Learning Sciences. Vol 10 N 4. NJ: Lawrence Erlbaum. Pp 365-415

\section{Scenario: one day in the life of Zora}

This scenario describes an actual engagement with Zora by young people participating in a summer workshop: Axel is a 12-year-old Jewish boy. He connects to the Zora multiuser environment ${ }^{l}$ from his home computer. His avatar ${ }^{2}$ has his own face. Axel quickly navigates through Zora's different public temples: the Jewish, the Baptist Church, the French Chateaux, and the Sports Arena. He is curious about the Jewish temple, maybe because it is the space he knows best. Upon entering, a picture of a rabbi welcomes him with a blessing. The temple is populated by Jewish characters and symbols. Axel clicks on a silver mezuzah ${ }^{3}$, which tells him a story about the meaning of the prayers it holds. Axel moves around the $3 D$ space and decides to add a television to the temple. He takes a snapshot of the movie "Schindler's list" and displays it in the TV.

While exploring the temple, Axel encounters Sybil, an older girl. They chat via their avatars and she invites him to add a television to her virtual home. Interesting objects populate Sibyl's home. There is a picture of her best friend, a couple of books, a tree and a dog. While Axel is reading the stories associated to them, the Zora mayor arrives. He says that a member of the community called for a meeting in the virtual city hall to discuss a new case: the creation of a virtual jail. Sybil and Axel teleport to the city hall. The case raises a lot of discussion amongst the kids. Some think that a jail is a waste of effort; instead, they argue, people should be punished by doing community service.

\footnotetext{
${ }^{1}$ In a graphical multi-user environment several users can interact with each other in real time. Users feel immersed in an artificial space containing visual representations of data, programs and other users.

${ }^{2}$ An avatar is a graphical representation of the user that can be controlled in real time.

${ }^{3}$ A mezuzah is a small piece of parchment inscribed with Biblical passages from Deuteronomy, which is rolled up in a container and affixed by many Jewish households to their door frames in conformity with Jewish law and as a sign of their faith.
} 
The Journal of the Learning Sciences. Vol 10 N 4. NJ: Lawrence Erlbaum. Pp 365-415

Others are concerned about technical issues such as how to lock prisoners in a virtual jail. After voting, majority decides that the jail won't be created.

\section{Introduction}

We live in a society where concepts of self, community and "what is right and wrong" are constantly changing. This makes it particularly challenging for young people to construct a sense of self and to identify their most cherished values. On the one hand, in today's fast paced world, most young people do not reserve spaces or times for self-reflection. On the other hand, there is an amounting pressure in schools and society to create learning environments to explore issues of identity and values. I propose identity construction environments as technological tools purposefully designed to support young people in learning about different aspects of the self, in particular personal and moral values.

Two research questions are at the heart of the work presented in this paper: What kind of learning environment will afford opportunities for young people to naturally engage in reflection and discussion about issues of identity, in particular personal and moral values? And, how can technologies have an impact on character and moral education? This paper contributes to the field of the learning sciences by showing an example of how to design and use technology to learn about the inner world. In particular three groups can benefit from reading it: First, the community of designers of technological learning environments, particularly in the area of computer supported collaborative learning (CSCL) and human computer interaction (HCI). This community can learn from the decisions that were made to design the identity construction environment presented in this paper, the Zora multi-user virtual world. Second, educators interested in moral and 
character education, civic or democratic education and education for multi-cultural understanding. These groups can benefit from learning how new technologies can be incorporated into their everyday practice and how these new tools might help them rethink the curricular content. Third, researchers and practitioners interested in exploring the possibilities that new technologies offer for personal, social and moral development. Math and science educators recognized the computer's potential long ago. However, people interested in the inner world have yet to discover how to appropriate the computer and design their own computational tools to influence new ways of thinking and behaving.

This paper is intended to highlight the potential of approaches that use new technologies to address learning about identity and values in a "learn by doing" or constructionist way. It is also aimed at mapping out a new area of application for collaborative multi-user environments. In the next subsection, I define what are identity construction environments and specify what type of learning they afford. Section three places the research in the context of related traditions of identity formation, moral development and constructionist learning. It also describes the tools used in educational and psychotherapeutic interventions and how they are integrated by identity construction environments. Section four provides a brief introduction to a particular identity construction environment, Zora, and describes the conceptual foundations upon which it was designed. Section five presents a description of a pilot workshop conducted with Zora, its methodology and evaluation methods. Section six describes several learning stories of young people involved in the creation of a virtual city and a participatory 
The Journal of the Learning Sciences. Vol 10 N 4. NJ: Lawrence Erlbaum. Pp 365-415

micro-community to explore issue of identity and values. In the seventh section, I revisit the design principles for identity construction environments in the light of the experience with Zora. Then I reflect on the learning stories and highlight open questions. Finally I conclude with future work that points to a new research agenda in the area of the learning sciences.

\subsection{What is an identity construction environment?}

Computers are powerful tools for self-exploration. Although they were originally conceived as instrumental machines, computers have another potential. They can serve as a "second self" or a psychological machine _not because they have a psychology but because they provoke us to think about our own (Turkle, 1984). However, most computer applications do not engage users in sophisticated learning about the self. I coined the term identity construction environments (ICE) to refer to technological tools purposefully designed to afford opportunities for exploring identity and engaging in reflection and discussion about personal and moral values. Given this definition, five design principles are meant to distinguish them from other technological tools for learning:

1. They are purposefully designed to help young people learn about their identity, particularly personal and moral values.

2. They are designed upon a theoretical model that positions identity as a complex and dynamic construction composed by conflicting values.

3. They afford opportunities for learners to design dynamic computational objects and spaces representing aspects of the self.

4. They offer opportunities for storytelling and they elicit narratives about the self. 
The Journal of the Learning Sciences. Vol 10 N 4. NJ: Lawrence Erlbaum. Pp 365-415

5. They support the creation of and participation in a community. No sense of self develops in a social vacuum.

In this paper, I show how the Zora identity construction environment embodies these design principles. I also show how teenagers in an intensive summer workshop built and inhabited a virtual city using Zora. They explored personal identity and values in a small micro-community self-organized by principles of participatory democracy.

\subsection{Learning afforded by identity construction environments}

What type of knowledge are learners likely to construct when engaging with ICE? Some use the terms self-knowledge, self-awareness or self-understanding to refer to mindfulness of one's own personality or individuality. Csikszentmihalyi and RochebergHalton (1981) call it cultivation and describe it as "the process of investing psychic energy so that one becomes conscious of the goals operating within oneself, among and between other persons, and in the environment”. Gardner (1983) calls it personal intelligence and describes it as involving two forms of knowledge intimately intermingled: intrapersonal, looking inward or a sense of self-awareness, and interpersonal, looking outward at other individuals and the community.

School standards have different labels for this type of knowledge: personal development, mental health, civics education and social responsibility. In general, standards do not integrate teaching about the self with teaching about life in community. They split these domains into two different curricular disciplines. For example, in Massachusetts, while the History and Social Science Curriculum focuses on civics (i.e. the rights and duties of 
citizens as participants in the community), the Health curriculum focuses on personal development and social awareness.

Identity construction environments are meant to engage young people in a learning process that integrates personal development with civic education. They support the formation of a person with a well-grounded sense of self that participates in community life.

\section{Theoretical foundations}

Both abstract theories and concrete tools inform the design of ICE such as Zora (see figure 1).

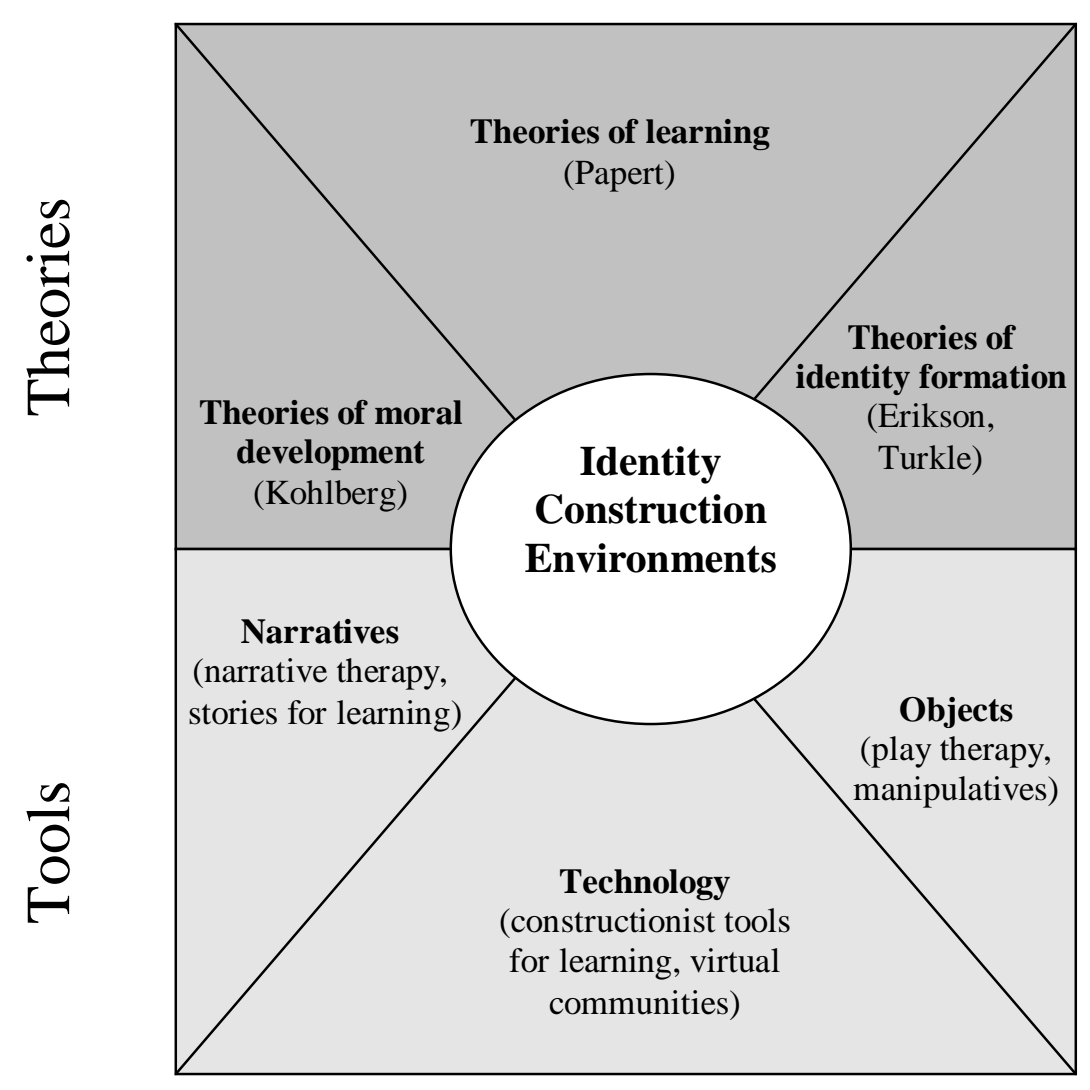

Figure 1: Identity construction environments' theoretical foundations 
The Journal of the Learning Sciences. Vol 10 N 4. NJ: Lawrence Erlbaum. Pp 365-415

In the next sub-sections I present each of the components, first the theories and then the tools, that form the foundations for the design and study of identity construction environments. I focus on how this foundational work informs the design of Zora.

\subsection{Theories of learning: constructionism}

Zora's design is based on the constructionist philosophy of education which asserts that people learn better when they are engaged building personally meaningful artifacts and sharing them with others in a community (Papert, 1980). By constructing an external object to reflect upon, people also construct internal knowledge. Constructionism has its roots on Piaget's constructivism (Piaget, 1965). However, while Piaget's theory was developed to explain how knowledge is constructed in our heads, Papert pays particular attention to the role of constructions in the world as a support for those in the head. Constructionism takes an epistemological perspective aimed at understanding the nature of how learning happens, but also an interventionist perspective aimed at producing a change in the way people learn. For this purpose, it views the computer as a powerful tool to support new ways of thinking and learning.

Within constructionism, research has looked at how immersive computer learning environments can support discussion of personal and cultural values. In these experiences, technology drew people into a higher level of mutual respect and collaboration, and an increasing sense of autonomy, interpersonal awareness and selfconfidence (Bisaillon, 1989; Hooper, 1994). For example, in the Cons-science project young kids and families used the LEGO Mindstorms robotic kit to design their own meaningful projects to convey personal, cultural and religious values (Bers \& Urrea, 
The Journal of the Learning Sciences. Vol 10 N 4. NJ: Lawrence Erlbaum. Pp 365-415

2000). Most of the self-motivated talk about values and identity amongst the participants in this experience happened before they started to build their projects, while choosing a value to work with, and at the end of the process, when showing off their projects to the community and receiving feedback. While building their projects, most of the participants engaged in conversations about the Lego Mindstorms building blocks and how to combine them. Since the building blocks of this kit are mostly sensors, motors and gears, people tended to discuss about concepts related to engineering and physics.

What kind of construction kit would evoke powerful ideas and conversation about identity and values, during the design and building process, and not only during the planning and debriefing stages? This question motivated the design of identity construction environments.For example, as I will show later in the paper, Zora offers building blocks composed of role models and anti-role models, narratives and values. Learners can create a virtual city populated with dynamic objects embodying aspects of a complex identity. While designing the virtual spaces within the city and organizing its commuity life they engage in reflection and conversation about personal and moral values.

One of the tenets of constructionism is the necessity of a community of learners to share projects and to explore ideas. Some research has focused on face-to-face learning communities (e.g., Falbel,1989 ;Shaw 1994; Pinkett, 2000) while other has explored different forms of on-line learning communities such as MUD's and bulletin boards (e.g., Bruckman 1998; Evard 1996). These experiences show that a constructionist approach to 
The Journal of the Learning Sciences. Vol 10 N 4. NJ: Lawrence Erlbaum. Pp 365-415

communities maximizes each individual's opportunities for learning, creative expression and content production and, at the same time, provides a support network. Zora takes advantage of this by engaging learners in the creation of a participatory micro-community in which personal and moral values are developed and put to test through on-line social interactions.

I use the term micro-community to refer to a safe space in which to experiment with new ways of thinking and behaving. This word is inspired by Papert's use of the term microworld to refer to a safe protected space that serves as an incubator of knowledge. For example, the LOGO language was meant to be a microworld to explore ideas about geometry and think in new ways about mathematics. Micro-communities have two distinguishable features that make them a safe space. First, the number of members is relatively small, therefore issues of social organization and democracy can be tackled without the problems encountered by large virtual communities (Kollock \& Smith, 1996). Second, in contrast with virtual communities in which members may or may not meet face to face, in micro-communities having regular face-to-face interactions is an important part of the learning experience.

\subsection{Theories of identity formation}

The design of identity construction environments such as Zora draws from the research of Erik Erikson in identity formation (Erikson, 1950; 1968) and the work of Sherry Turkle on technology and identity (Turkle, 1984; 1995). Erikson studied the process of identity formation in healthy personalities. He focused on the growth and crises of identity during the different stages of the life cycle. He looked at adolescence as a critical time for the 
The Journal of the Learning Sciences. Vol 10 N 4. NJ: Lawrence Erlbaum. Pp 365-415

formation of a sense of self, therefore his work is particularly relevant to my research.

Erikson studied the interplay between the psychological and the social, the developmental and the historical, the cognitive and the affective. This integrated view of identity informs the research presented in this paper. In his vision, identity is characterized by a tension between differentiation and identification: the need to find boundaries between self and others, and the need for integration into a major whole, constituted by family, culture and society.

In Zora learners explore this tension by designing a unique virtual autotopography, which includes both personal homes and public spaces or temples. An autotopography is a spatial representation of identity composed by collections of symbolically significant objects (Gonzalez, 1995). In the case of Zora, virtual autotopographies give materiality and concreteness to intangible aspects of the self. For example, the personal homes represent a core sense of self, thus they refer to the "differentiation" aspect of identity formation that Erikson talks about. The public temples focus on the integration into a culture and society.

Erikson wrote that a "sense of identity provides the ability to experience one's self as something that has continuity and sameness and to act accordingly" (Erikson, 1950, pp 42). Therefore, while designing Zora, it was important to provide an environment in which learners could engage in reflection, while creating their virtual autotopographies, and actions, while participating in a community. 
The Journal of the Learning Sciences. Vol 10 N 4. NJ: Lawrence Erlbaum. Pp 365-415

Sherry Turkle's research applied Erikson's theoretical framework to the study of how people use MUDs, and other examples of computer mediated communication on the Internet, as a "social laboratory for experimenting with the constructions and reconstructions of self that characterize postmodern life" (Turkle, 1995). For example, she borrowed his notion of "moratorium", a time of constant experimentation, interaction and reflection in the adolescent's life, and proposed that virtual worlds can provide spaces for this moratorium. Zora serves as a "moratorium" space with design features that encourage young people to explore further and engage in a learning experience about the self. These design features are described in section 5.

\subsection{Theories of moral development}

The research presented in this paper is informed by the work of Lawrence Kohlberg on moral development Although Kohlberg is most well known for his psychological model of stages of moral development that progress from highly egocentric value judgements to reasoning about abstract universal moral principles (Kohlberg, 1976), he has also contributed to the field of moral education by proposing the "just community" model (Kohlberg, 1985). This approach proposes that the involvement in participatory democracy, social institutions, group decision-making and self-government is critical to shaping an individual's moral development ${ }^{4}$. Therefore, educational interventions should focus on both moral thinking and the moral lives of children (Coles,1986).

As revisionist work on Kohlberg proposed, much of the unexplored promise of the Kohlbergian project lies in the "just community" model instead of in the stages model 
(Reed, 1997). Zora provides an environment to support the formation of a virtual just community. It involves learners in the creation of a participatory micro-community where they can put to test personal and moral values through actions and conversations. For example, in Zora's City hall people engaged in powerful conversations about dilemmas as well as in the development of a just community in which values are not only a matter of analysis and reflection but also of everyday action and behavior.

The assumption behind Kohlberg's stages of moral development is that there is a universal progression from a concrete to an abstract way of thinking about moral issues. The idea that the highest stage of development involves abstraction and logical reasoning has been criticized by showing a difference in the way in which men and women reason about morality (Gilligan,1982) and by emphasizing the validity of different thinking styles (Papert, 1987; Turkle \& Papert, 1992). Identity construction environments support the co-existence of a plurality of thinking styles. For example, Zora supports a plurality of styles for exploring values by providing two different design features. Learners can enter their values and corresponding definitions directly into a collaborative values dictionary tool, thus exploring values as universal abstractions disconnected from particular instances. Or, they can assign values and definitions as attributes of the objects they construct in the virtual city, thus exploring values in a more concrete way, grounded in experiences represented by those objects.

\footnotetext{
${ }^{4}$ The core of the Just Community approach is the establishment of a participatory democracy in the learning environment. It has been implemented in schools as well as prisons (Kohlberg, 1985; Hickey \& Scharf, 1980).
} 
The Journal of the Learning Sciences. Vol 10 N 4. NJ: Lawrence Erlbaum. Pp 365-415

\subsection{Tools}

The design of identity construction environments is informed by the tools used in educational and therapeutic initiatives that understand identity as a complex construction. In the US, there is a great divide between these two types of interventions. On the one hand, educational interventions are mostly aimed at issues of multiculturalism (which limit identity to ethnicity) or character formation (which limit identity to morality) and do not focus on personal psychological issues. On the other hand, therapeutic interventions are rarely conceived as a learning process that everyone benefits from going through. The general perception is that therapy serves to "fix" what is not working and therefore it is only for people with pathologies. Unfortunately, this view ignores the fact that therapeutic interventions focus on identity as a holistic issue and provide tools to engage in a learning process about the self that everyone benefits from. Zora, as an identity construction environment, is designed to help bridge the divide between educational and therapeutic interventions. Three types of tools inform its design: narratives, objects and learning technologies.

\subsubsection{Narratives: their role in identity formation and moral development} The Zora identity construction environment is inspired by the use of storytelling in different forms of psychotherapy (Wigren, 1994; Rosen, 1982). In particular, Zora's use of narrative is inspired by narrative therapy which understands identity as constructed through the stories we tell and re-tell about our lives and proposes interventions aimed at helping people generate alternative stories to find new meanings (White \& Epston, 1980). In Zora, identity is constructed by the objects placed in the virtual autotopographies and the narrative attributes given to them (both in terms of static stories and dynamic 
The Journal of the Learning Sciences. Vol 10 N 4. NJ: Lawrence Erlbaum. Pp 365-415

conversational storytelling behaviors). As new objects and stories are created, new perceptions of identity develop.

Narrative also plays an important role in moral development (Tappan \& Brown, 1989; Jhonson, 1993); therefore it has a long and universal tradition in programs aimed at moral and character education. Stories such as fairy tales or myths, and biographies of historical or religious figures are used to introduce universal human values and role models to the children (Bennett, 1993; Coles 1989). In some cases, storytelling's potential has been augmented by the use of computation. For example, Roger Schank's research group, at the Institute for the Learning Sciences, has used stories to design ASK systems. In this kind of hypermedia the user provides questions and the experts, represented by the ASK system, provide the answers in the form of stories (Schank, 1994).

In previous work, I designed and used Kaleidostories, a web-based identity construction environment to explore role models and values in an on-line community (Bers, 1998). The system guides users in the creation of a personal on-line portrait with narratives about the present and the future (e.g. who or what do I want to become?), and stories about personal role models. Kaleidostories' design, however, was not enough to facilitate the passage from knowledge to action, from identity expression to identity construction. One of its shortcomings was that it lacked the capability to include direct, synchronous communication through real-time chat. It also lacked the flexibility to express a more complex sense of self, in which other aspects beyond role models and narrative descriptions of personal values were explored. 
From my experience with Kaleidostories I learned two lessons. First, the importance of exploiting the potential of computation to create a virtual environment which enables its members to "act-out" in the community. It is not enough to limit computation to networking and visualization, as Kaleidostories does. Second, and equally important, is the need for a fun environment that would engage participants to use it on their own for a long a period of time. Kaleidostories' interface was not compelling and required a big effort from the teachers in order to engage students and keep them on track.

\subsubsection{Objects to introspect with}

Objects have both an instrumental function (what they can do) and an evocative function (what they mean). Because of this duality, objects are a rich material to work with. For example, play therapy has paid particular attention to the role that diverse objects play in children's exploration of their identity. For example, they have used puppets, marionettes, arts material and various toys that engage children in symbolic enactment to express their feelings and explore their sense of self (Barnes, 1996). Inspired by this tradition, identity construction environments engage learners in the design of personally meaningful objects. In particular, Zora's use of objects has been inspired by work that studied the meaning of the most cherished objects that people put in their homes (Csikszentmihalyi \& Rochberg-Halton, 1981). These objects not only have a decorative function, but also say a lot about people's value system and personal identity. In Zora, the objects that young people put in their virtual homes represent aspects of the self and are explicitly associated with personal and moral values. 
The Journal of the Learning Sciences. Vol 10 N 4. NJ: Lawrence Erlbaum. Pp 365-415

In education there is a long-standing tradition that shows the potential of using "objects to think with". For example, Montessori and Fröbel designed a number of manipulatives or "gifts" to help young kids develop deeper understandings of mathematical concepts such as number, size, and shape (Brosterman, 1997). In the same spirit, "digital manipulatives" seek to expand the range of concepts that children can explore, particularly dynamic processes, by embedding computational power in traditional children's toys such as blocks, beads, and balls (Resnick et al, 2000).

Zora explores the potential of using objects to help people think and learn in new ways about identity and values. It integrates the use of virtual objects and narratives by appropriating the object-oriented programming paradigm. Within this framework, computational objects are modeled after real-world objects that have both attributes and behaviors, which allow them to communicate with other objects or the outside world.

The object-oriented metaphor is particularly useful in providing ways of thinking about values in concrete rather than abstract ways. For example, it highlights the relationship between identity and personal and moral values. The answer to the question "Who am I? ", is represented by the objects that learners decide to put in their virtual autotopographies. A flag of the parents' homeland, a picture of a best friend, a soccer ball, a piece of the favorite cake, are all examples of objects that represent fragments of important aspects of the self. The answer to "what are my cherished values?" is represented by the value attributes associated with those objects. For example, the value "honoring your ancestors" linked to the flag, the value "friendship" associated with the 
The Journal of the Learning Sciences. Vol 10 N 4. NJ: Lawrence Erlbaum. Pp 365-415

best friend's picture, "productive exercise" to the soccer ball, and "health" to the cake. While making an explicit decision about which objects would become part of their virtual homes, and what kinds of values they convey, learners engage in self-reflection. In the process, they ground abstract values with concrete, personally meaningful objects.

\subsubsection{Technological Tools for Learning}

The work presented in this paper is deeply influenced by research on the design of constructionist learning environments (Resnick et al 1996). Two key aspects from this work inform the design of ICE. First, when engaging with these environments, learners can explore new ideas in connection to their personal interests and motivations. Second, constructionist learning environments provide tools for learners to become designers of their own projects. Sections 4 and 5 present the tools that Zora offers to designers.

Research on networked learning environments that afford quick access to a wide range of information and resources, as well as communication mechanisms, shows new ways of doing inquiry learning in a collaborative way and engaging in critical debate (Songer, 1996; Scardamalia \& Bereiter, 1994; Pea et al. 1994; Edelson, 1999). While most of this work is aimed at reproducing the characteristics of a community doing scientific inquiry, identity construction environments are also in line with virtual communities that enable new expressions of social life and support networks (Morningstar \& Farmer, 1990; Kollock \& Smith, 1998; Rheingold, 1993; Donath, 1996). Although this research informs Zora in terms of design features needed to foster community and ways of managing its organization, the research presented in this paper does not study collaboration or the evolution of virtual communities and on-line identities. The choice of a multi-user 
The Journal of the Learning Sciences. Vol 10 N 4. NJ: Lawrence Erlbaum. Pp 365-415

environment, that enables the formation of community, was purely aimed at providing a social context for exploring identity and personal and moral values.

\section{What is Zora?}

The name Zora was inspired by one of the imaginary cities described by Italo Calvino: "This city is like a honeycomb in whose cells each of us can place the things we want to remember...So the world's most wise people are those who know Zora." (Calvino, 1972). The hope is that by engaging with the Zora identity construction environment, kids will also become wiser by knowing who they are.

Zora is a 3-D multi-user environment particularly designed to help young people explore identity as constructed by diverse and conflicting aspects and values. In the same spirit as other constructionist virtual worlds such as the text-based MOOSE Crossing (Bruckman, 1994) and Pueblo (Bobrow et al, 1995) and the graphical Pet Park (DeBonte, 1996), kids can populate the world with their own interactive creations. They can design objects, characters and spaces as representations that make up a complex self, as well as a virtual micro-community in which personal and moral values are realized and put to test. Users are graphically represented by avatars. An avatar construction kit allows the design of personal avatars and their corresponding graphical gestures (i.e. sleep, smile, upset, etc).

Users can navigate around the virtual city by either "teleporting" from one room to another using a pop down menu or going through the portals in each room. They can converse with others in real-time through a graphical chat system. They can also construct the city's private and public spaces by using one of the following templates: 
personal homes, community centers and temples. Temples are shared public spaces that represent cultural traditions or group interests. Users can design the walls, the ceiling and the floor of their spaces with any texture. For example, they can import a digital picture of their favorite wallpaper.

Zora is an object-oriented environment, meaning that users can make new artifacts by cloning existing ones and inheriting its attributes and behaviors. Figure 2 shows Zora's initial inheritance model. It grows as users create their own objects.

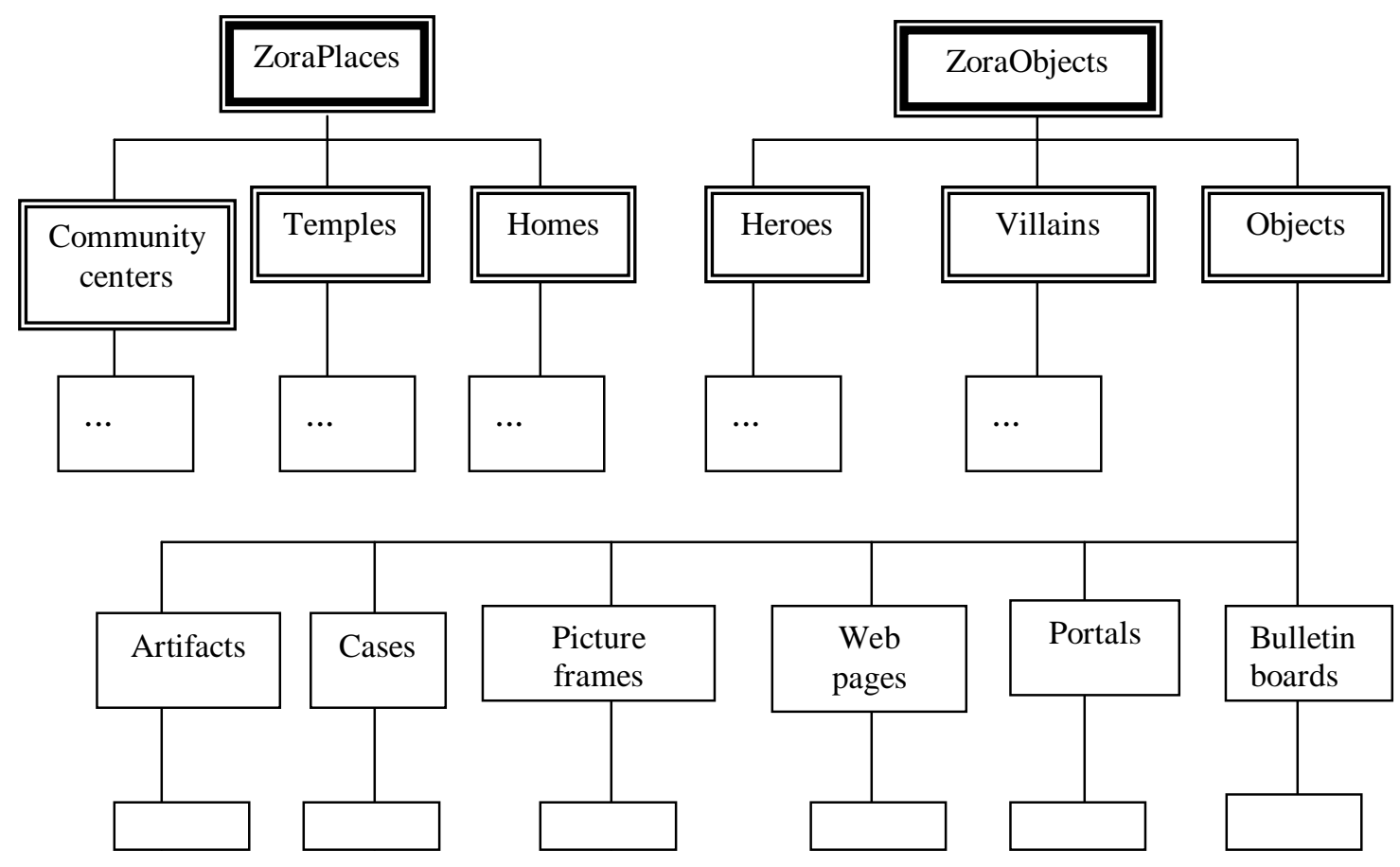

Figure 2: Zora's objects and class inheritance

The Zora system seeds all objects with three different kinds of attributes that need to be personalized by the children. The presentation attributes determine object's graphical appearance and motion. The administration attributes determine who owns the object and 
The Journal of the Learning Sciences. Vol 10 N 4. NJ: Lawrence Erlbaum. Pp 365-415

therefore who can edit it, and who has permission to decide if the artifact can be cloned. The narrative attributes (i.e. textual descriptions, stories, values and conversations) structure a way of thinking about objects that highlights their potential to carry ideas. Users can write stories and associate them with keywords to be used while programming a conversation for the object, as well as write values and associate them with definitions.

For example, during a workshop, 12 year old Sheila created in her personal room three heroes, Aniga amouse, Eve and LetiebelelegangaTsesbe, and objects such as a TV, a Bible, a horse, a picture of popular video game and a lamp. Sheila used words in a skillful way to convey the personal meaning she attributed to her objects and why she chose her heroes. For example, she wrote the following story for Eve. "Eve is a rapper. She is my role model because she started out with nothing then she rose her way to the top, and never stopped trying... Now she has a number one song, and is constantly appearing in commercials, and other music videos." Sheila also associated the objects and characters with values and defined them. For example, she attached the value "pride" to her hero Eve and defined it as: "It is your confidence in yourself and being able to express and stand-up for yourself without being afraid of what other people will think of you."

Zora is implemented using Microsoft's Virtual Worlds research platform, a software development kit for building distributed 3D graphical multi-user environments that provides synchronous and asynchronous communication, object persistence, web integration, and customizable user interfaces (Vellon et al, 1995). In order to understand how Zora and the Vworlds platform fit together and Zora's implementation, four concepts need to be made clear: 
The Journal of the Learning Sciences. Vol 10 N 4. NJ: Lawrence Erlbaum. Pp 365-415

- Zora is a world created with the Vworlds platform. The platform was implemented with the goal of supporting developers to create their own virtual worlds without dealing with lower level details of networking, graphics, etc. Different worlds have been created with the VWorlds platform by different universities and research labs (see http://research.microsoft.com/vwg/\#projects).

- Zora implements new objects, properties and methods to meet the particular content needs of an ICE. As shown in figure 2, Zora implements the base class ZoraObject with three children objects: objects, heroes and villains. Of the six children that objects have, four new ones were implemented (artifacts, cases, bulletin boards and picture frames) and two borrowed from Vworlds standard objects (web pages, that establish a web link to a website, and room portals, which allow navigation from one room to the other). All of these have the following properties: description, motion, pictures, stories, values and conversation. The objects only differ from each other in the 3D shape that kids can personalize with their own pictures.

- Zora modifies the Vworlds user interface. Since Zora is an ICE, its interface was augmented with features such as a collaborative values dictionary, the narrative-based objects' attributes, the conversational behaviors for objects, the possibility to add heroes and villains and a modified avatar's profile. Figure 3 shows the Zora interface. 


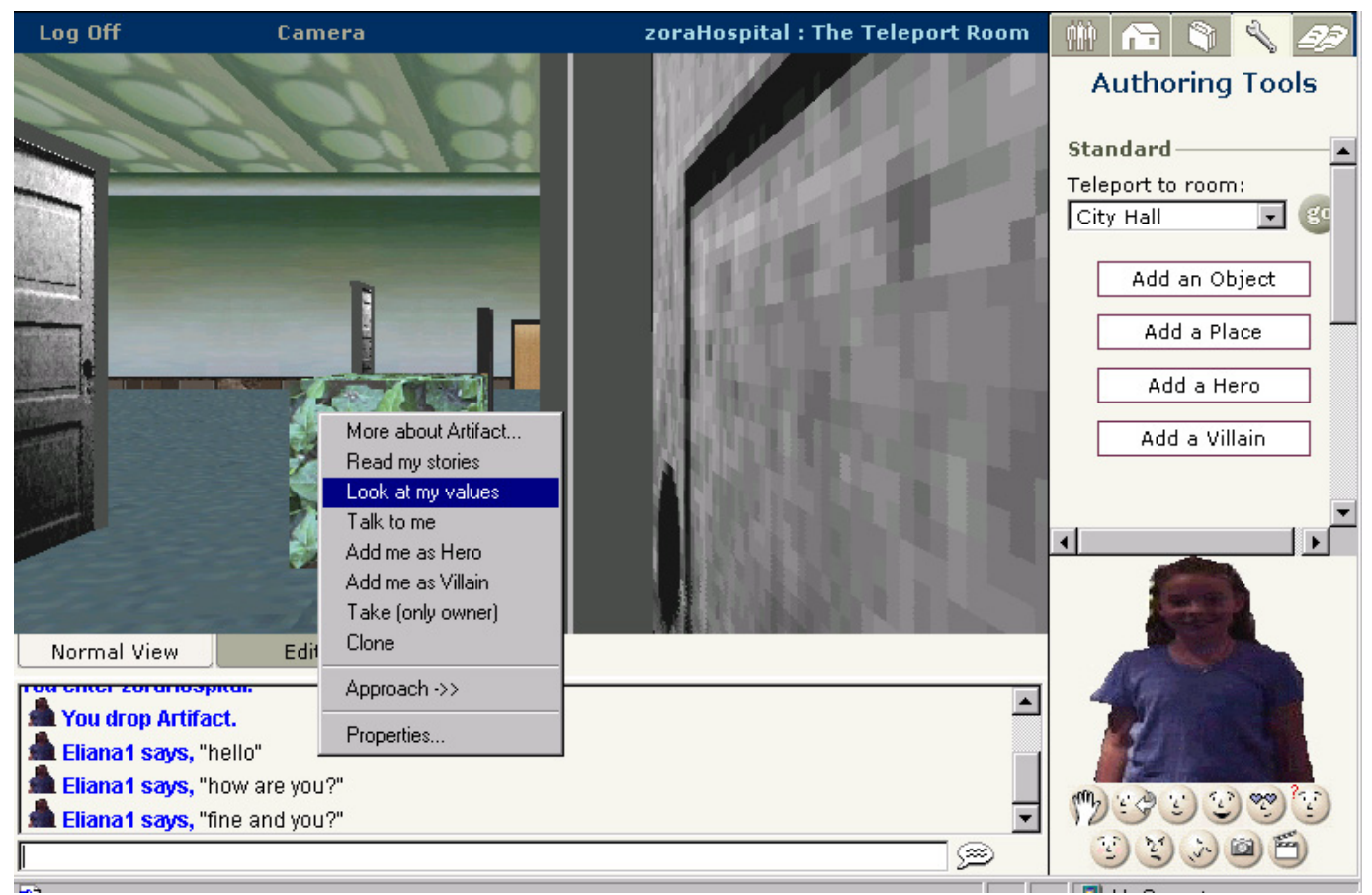

Figure 3: Zora's interface

- Zora offers an authoring layer easy for children to use. Although the Vworlds platform has an authoring client with tools that allow users to build and manipulate 3D worlds, this needed to be modified in major ways. First, in order to keep it simple for children, most of the command line style script interface tools were replaced with direct controls. The tools for 3D model manipulation, lighting, mesh color and texture control were simplified and new features were added so that children could upload their own pictures, instead of only using the available library.

- Zora offers tools to evaluate the learning experience. In order to facilitate the evaluation of the experience, the Zora system logs, with date and time, everything users say or do on-line. Analysis of system logs is a well-known practice in research on computer-mediated communication (Herring, 1996). By analyzing the log, the researcher or teacher can re-construct what happened on-line during any period of time. However, so much information can be confusing. A Zora log parser was 
implemented in order to parse the system logs according to the specific needs of each project. The Zora log parser organizes the information in a format easy to read and gives control of the variables to retrieve and display as separate categories (see figure $4)$.

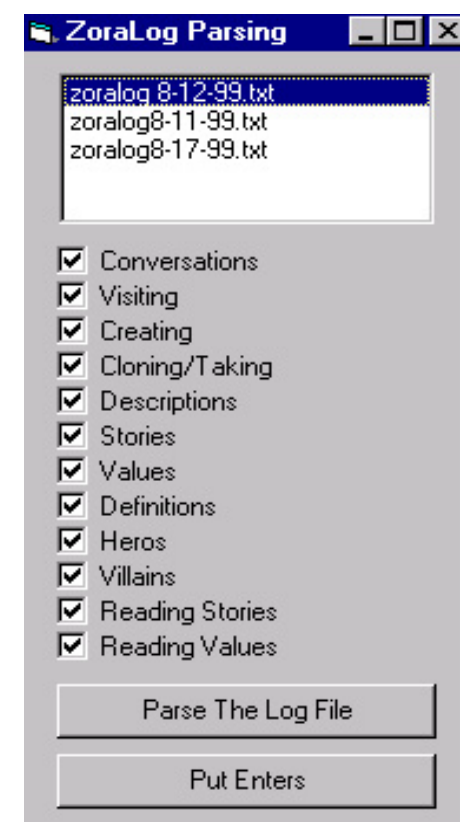

Figure 4 shows the Zora log parser.

\subsection{Conceptual foundations of Zora's system design}

Identity construction environments afford exploration of identity, in particular personal and moral values. In the design world, the term affordance refers to the attributes of the thing that determine how the thing could possibly be used (Norman, 1988). When the thing is a technological learning environment, like Zora, "affordance" not only refers to usability but also to content to be learned. Three questions need to be asked of Zora's affordances: First, what are the conceptual foundations upon which it was designed? Second, how can it be used for learning? Third, for what specific content does it give access to learners? In this section I respond to these questions by highlighting the conceptual foundations that guided Zora's design, the design features that supported 
learning and the kinds of activities learners engaged in Zora. The following table summarizes the structure of the remainder of this section (see figure 5).

\begin{tabular}{|c|c|c|}
\hline Conceptual foundations & Design features & Afforded activities \\
\hline \multirow[t]{2}{*}{ 4.1.1 Constructionism } & Authoring tools & Learners as designers. \\
\hline & 3D space & $\begin{array}{l}\text { Creating and navigating } \\
\text { aesthetically pleasant spaces. }\end{array}$ \\
\hline \multirow[t]{3}{*}{$\begin{array}{l}\text { 4.1.2 Identity as a complex } \\
\text { construction }\end{array}$} & Object-oriented system & $\begin{array}{l}\text { Creating and cloning objects } \\
\text { representing aspects of self. }\end{array}$ \\
\hline & Virtual places & $\begin{array}{l}\text { Designing virtual places as } \\
\text { spatial representations of } \\
\text { identity. Engaging in } \\
\text { introspection. }\end{array}$ \\
\hline & Avatar's profile & $\begin{array}{l}\text { Creating virtual profiles as } \\
\text { textual representations of } \\
\text { identity. Taking pictures to } \\
\text { express different emotions } \\
\text { and creating biographies, } \\
\text { values, heroes and villains. }\end{array}$ \\
\hline \multirow[t]{3}{*}{$\begin{array}{l}\text { 4.1.3. Exploring values as } \\
\text { aspects of identity }\end{array}$} & $\begin{array}{l}\text { Narrative attributes of } \\
\text { objects }\end{array}$ & $\begin{array}{l}\text { Defining the values that } \\
\text { objects carry and specifying } \\
\text { the meaning attributed to } \\
\text { them. Anchoring values to } \\
\text { concrete experiences. }\end{array}$ \\
\hline & Conversations & $\begin{array}{l}\text { Programming interactions for } \\
\text { objects and engaging in } \\
\text { perspective taking. }\end{array}$ \\
\hline & $\begin{array}{l}\text { Collaborative values } \\
\text { dictionary }\end{array}$ & $\begin{array}{l}\text { Entering values and } \\
\text { definitions. Understanding } \\
\text { values as abstract principles. }\end{array}$ \\
\hline \multirow{3}{*}{$\begin{array}{l}\text { 4.1.4. Need of a community } \\
\text { to develop sense of self and } \\
\text { values }\end{array}$} & Multi-user environment & $\begin{array}{l}\text { Creating a virtual community } \\
\text { for reflection and action. }\end{array}$ \\
\hline & $\begin{array}{l}\text { Multiple modes of } \\
\text { interaction }\end{array}$ & $\begin{array}{l}\text { Chatting, gesturing, using } \\
\text { bulletin board, face-to-face. }\end{array}$ \\
\hline & Cases & $\begin{array}{l}\text { Creating and discussing cases, } \\
\text { fostering participation in the } \\
\text { community. }\end{array}$ \\
\hline
\end{tabular}

Figure 5: The conceptual foundations of Zora's design features as well as the activities they afford.

\subsubsection{Conceptual foundation: Constructionism}

- Authoring tools: To engage in constructionist learning, Zora users need easy-to-use authoring tools to design and build their virtual city (see figure 6). Among these tools 
are object types important for the exploration and expression of identity. For example, empty templates of positive and negative models of identification, called heroes and villains. As shown in the class inheritance model in figure 2, users can create four different types of objects: virtual places, objects, heroes and villains. Although in terms of the underlying computational system and their attributes, objects, heroes and villains are the same type of computational object, it was important to present them distinctly to the learners. The rationale underlying this design decision was to highlight that the objects and the models of identification created in Zora, represent diverse aspects of a complex identity and they affect us in both positive and negative ways.

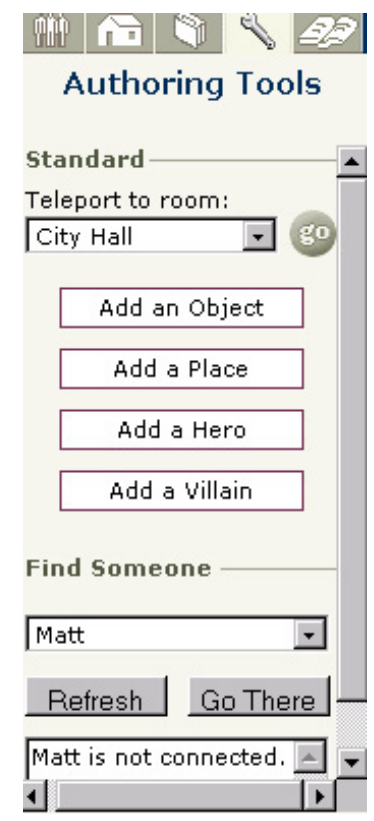

Figure 6: tools for designers

- The use of 3D: One of the tenets of constructionism is that learners need to naturally engage with their building materials to explore the content matter. In Zora, the use of 3D serves such engagement purposes. The three-dimensionality and the navigation 
The Journal of the Learning Sciences. Vol 10 N 4. NJ: Lawrence Erlbaum. Pp 365-415

around Zora provide an esthetically pleasant environment that has similarities with popular video games. The intent was for users to see Zora as a captivating game with which to engage for long periods of time rather than viewing it as educational software. This self-motivated long-term engagement is essential to explore identity and values.

\subsubsection{Conceptual foundation: Identity as a complex construction}

- Object-oriented system: Zora is an object-oriented environment where users can make new artifacts. They can clone existing ones and have them inherit their attributes and behaviors. Then they can personalize them with properties such as pictures, stories, conversations and values. The properties of objects set the structure that define the object as well as the frame of mind through which the object is thought upon. For example, if objects have attributes that set their motion, the learner most probably will be thinking about direction, speed, X and Y coordinates. In Zora, objects have properties that, besides defining their shape and functionality, also specify the meaning or personal and moral values that people assign to them (see figure 7). For example, when a fifteen year old assigned the value "wealth" to a picture of a dollar and wrote "I say that money is the symbol of material wealth. Its powers are vast but limited only to the material world", he was thinking about the meaning that money carries. When other kids clone the object, its values attributes are inherited but their definitions are not. Thus objects become collective repositories of meaning. This design decision was made because of the opportunities for new ways of thinking about values that object-oriented systems afford. For example, the notion of inheritance provides a nice metaphor to think about how personal and moral values 
are passed along from generation to generation but in each one, they get reinstantiated, hence re-appropriated and imbued with new meanings according to the new context.

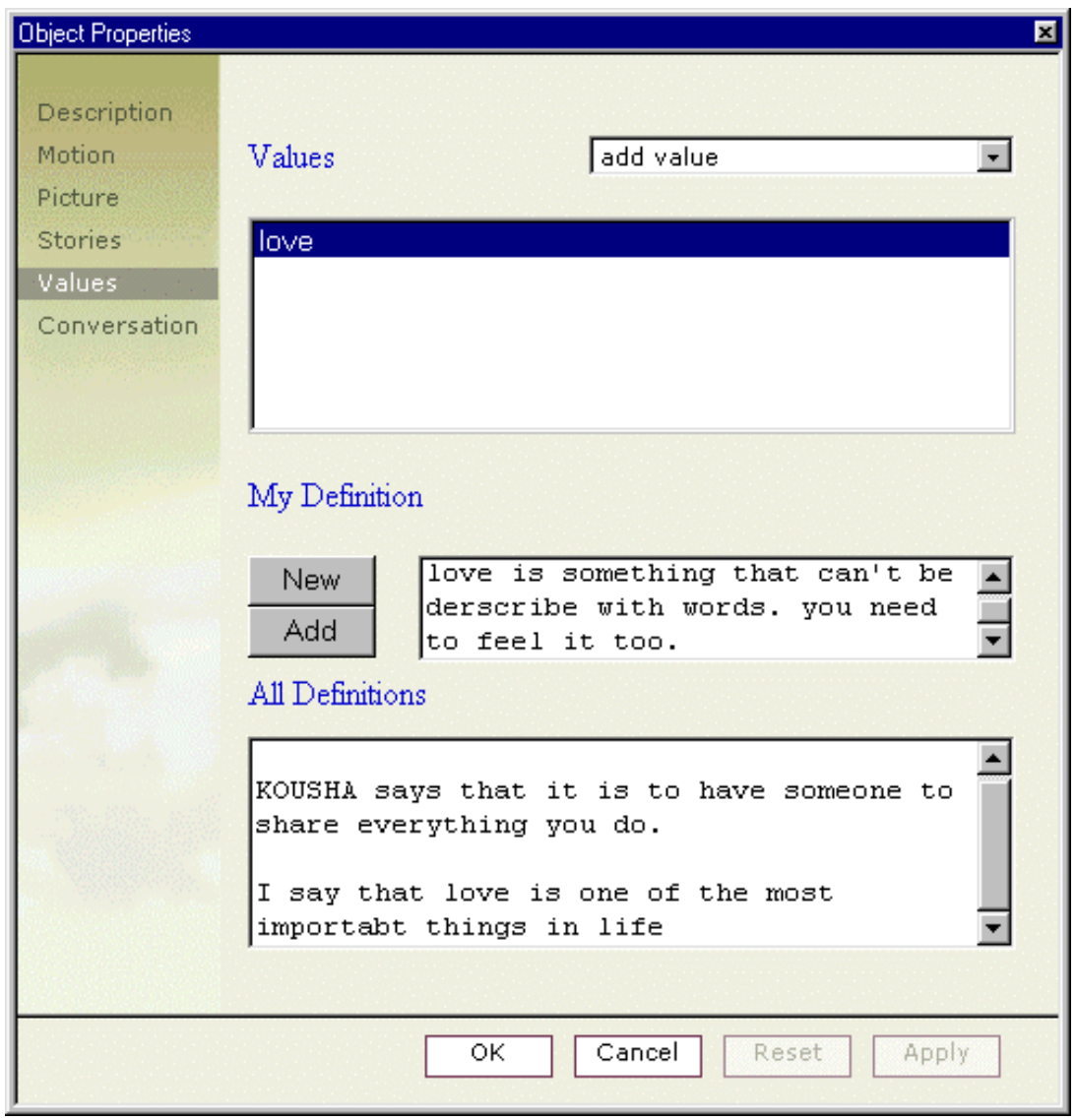

Figure 7: interface to create a value attribute associated to an object

- The virtual places: Learners can personalize their virtual places by selecting different textures and colors for the walls, floor and ceiling. It was a design decision to include amongst the tools for building the virtual spaces three distinct templates: personal homes, community centers and public temples. Although the underlying system architecture is the same for all three, having them as separate categories engaged learners in different thinking processes about their identity. While creating a personal home, kids think about designing a virtual space that contains different 
The Journal of the Learning Sciences. Vol 10 N 4. NJ: Lawrence Erlbaum. Pp 365-415

aspects of the self. The personal home displays those objects and characters that kids believe to be constitutive of who they are. While creating a virtual temple, kids design a space that represents cultural traditions or group interests dear to them. While creating community centers, they think about the need of social institutions for community life to flourish. For example, one of the girls working remotely created a Junk shop to drop objects that "no one wants around but no one wants to delete". This space became popular (by the end of the workshop it had 33 objects) and was regulated by a law that said that it could never be too full. It became a community space for informal social interactions. While the City hall was invested with a sense of "important business", the Junk shop was a space to get together and chat in an informal way.

- The avatar's profile: The avatar's profile is a textual representation of identity that contains an autobiography, links to the user's personal values and their definitions, and links to the user's heroes and villains (see figure 8). It also provides access to the avatar construction kit so users can customize the graphical appearance of their avatars by importing their own pictures. This kit allows the design of avatars with body gestures expressing different emotions. The rationale behind the creation of the avatar profile was to display in an integrated way different aspects of the user's identity. It also enables users to quickly access information about each other. 


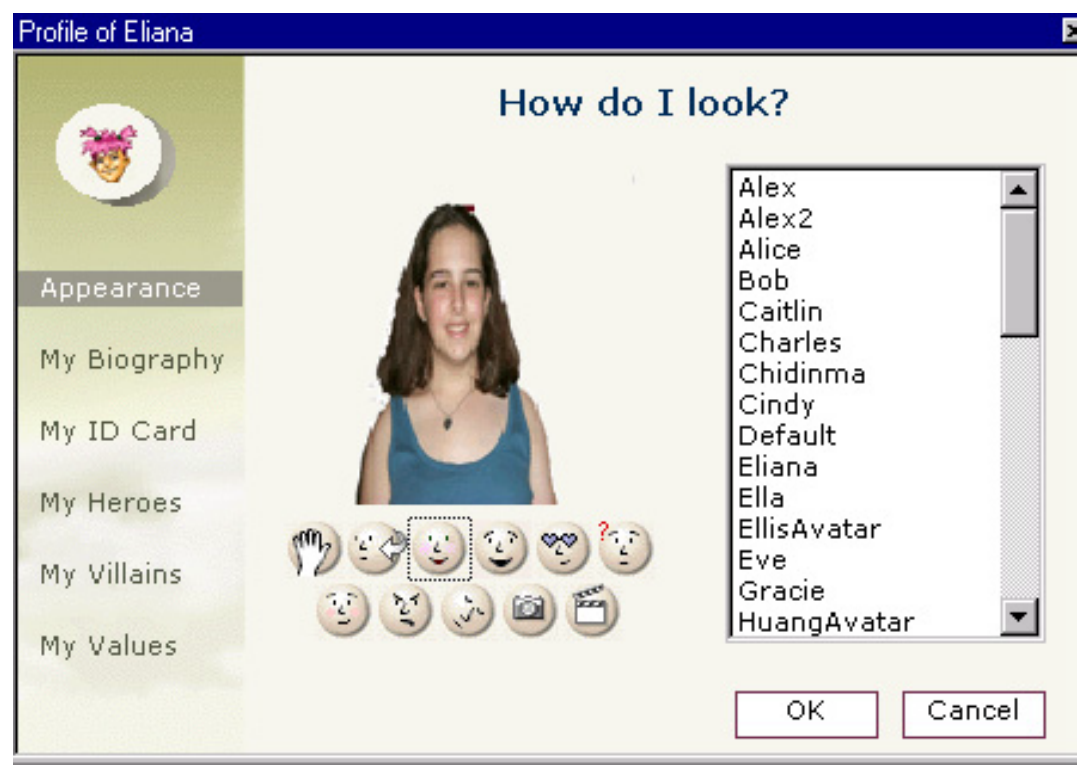

Figure 8: The avatar's profile

\subsubsection{Conceptual Foundation: Exploring values as aspects of identity}

- The narrative attributes of objects: Since narrative plays an important role in the construction of identity (Polkinghorne, 1988), and the development of personal and moral values (Tappan \& Brown, 1989; Johnson, 1993), the attributes that define the meaning of Zora objects are narrative-based: stories, values and conversations (see figure 9). The rationale behind this design decision was to foster thinking about objects in terms of what they mean and their relationship to personal values and identity, and not only in terms of their aesthetics and functionality. For example, a twelve-year-old created the hero "Anne Gunning" and wrote the following story about her: "Ms. Gunning is the Nicest Gym teacher in the whole school. She is also my Basketball and Softball coach and she never gets mad. She always tells me to try my best and reach my goals in sports. She's Great." She also attached to her hero the value "pride" and defined it as "Pride is when u feel good about yourself and feel that you have no need to be afraid. Feeling good about yourself makes yourself feel really 
good inside." This young girl used narrative (both in the story and in the definition of the value "pride") to convey what her hero means to her and how Ms. Gunning helps her feel proud about herself.

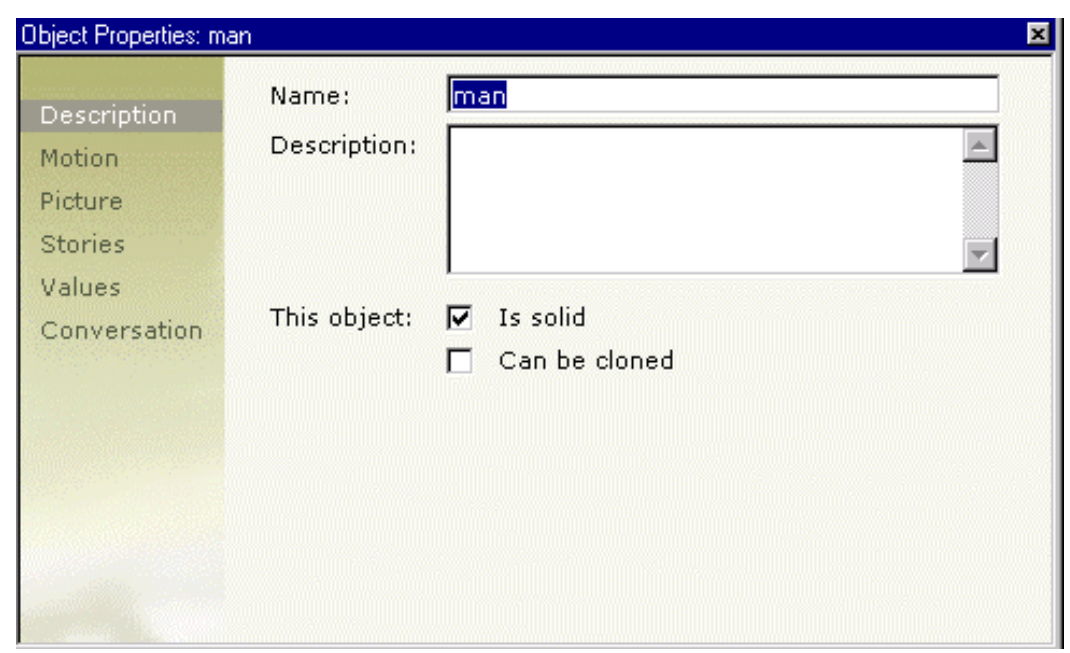

Figure 9: The five properties of objects, heroes and villains are displayed on the menu on the left

- Conversations: Users can program objects to engage in conversations, by describing the underlying turn-taking rules between user and object (see figure 10). While programming interactive conversations, learners engage in perspective taking. Understanding other people's motivations and actions is a fundamental mechanism for broadening one's perspective and recognizing that events can be understood through multiple points of view (Selman, 1980). As shown in previous work done with SAGE (Bers \& Cassell, 1998), designing conversations allows children to decenter and move out of the phase of egocentrism where one cannot differentiate somebody else's point of view from one's own. In Zora the learner becomes a "protean self"5 (Lifton, *). Namely, his or her identity maintains its sameness and

\footnotetext{
${ }^{5}$ Robert J. Lifton uses the word "protean self" (after Proteus, the Greek sea god of many forms) to refer to the fluid transformations and shifting of personalities, while maintaining a core sense of integrated self.
} 
inner stability, represented by the avatar, but at the same time takes different roles and points of view by talking through different characters, or objects, that he or she has programmed. For example, learners can program interactions that in English read like: " if the [visiting avatar] and me [the creator of this object] have the same heroes in the avatar's profile list, then say 'hi, I think that we have something in common and tell [story 1], otherwise say 'bye'”. The programming language gives flexibility to users to program scripts (what is said by the object) and to control the types of interactions (complexity of the branching). In order to explicitly support the exploration of identity, the language is seeded with variables such as "shared heroes", "shared villains" "shared values" and "stories from database". Learners can use these variables, and create new ones, as well as use commands such as "tell story".

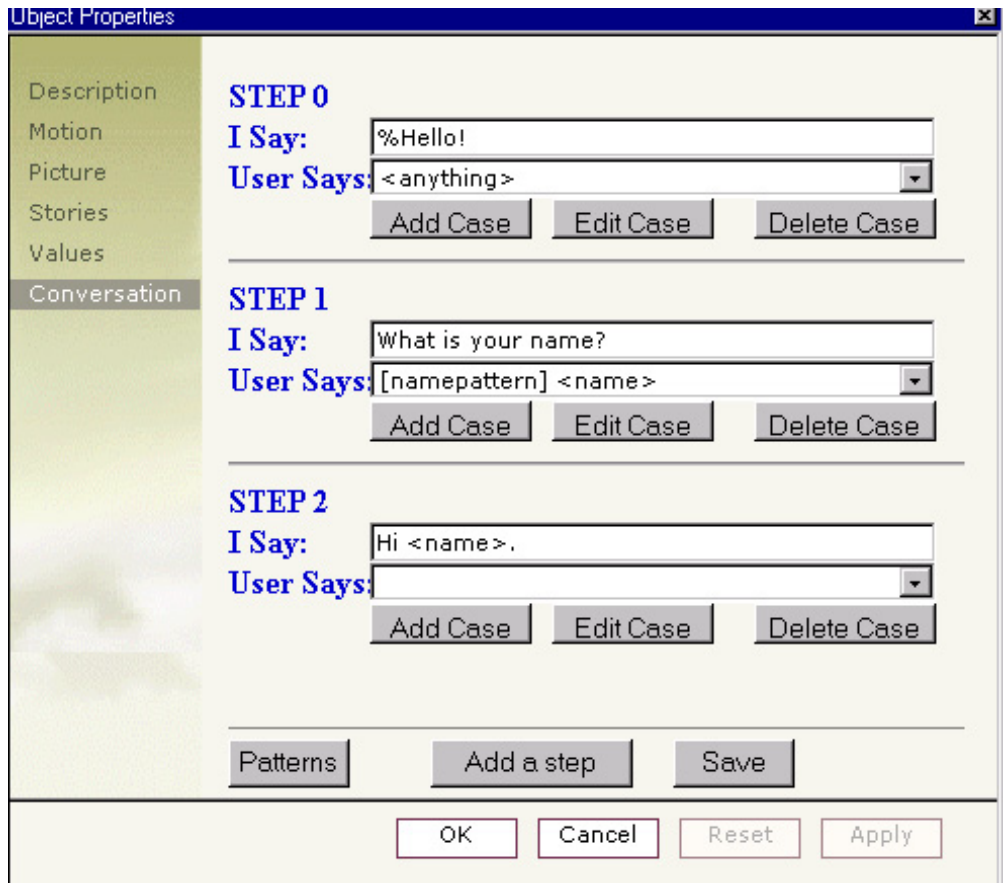

Figure 10: the programming interface to design conversations

- The collaborative values dictionary: The dictionary is a compendium of all the values, and their multiple definitions, held by the Zora community. At the beginning 
of a Zora experience, the dictionary is empty. As learners populate the virtual city with objects and characters and define the values and definitions associated with them, the dictionary starts to fill up (see figure 11). The collaborative values dictionary was designed to allow kids to 1) browse its content and observe clashes between different definitions for a same value in order to trigger interesting conversations, and 2) enter new values and definitions independently from grounding them in objects in the virtual world. The dictionary engages users in an abstract way of thinking about values by disassociating them from any specific instance or object. For example, in the experience reported in this paper, the values dictionary of the city had 37 values with a total of 95 definitions. The most popular were "entertainment" with 8 definitions, "love" with 7 definitions, "communication" and "productive exercise" with 5 definitions each.

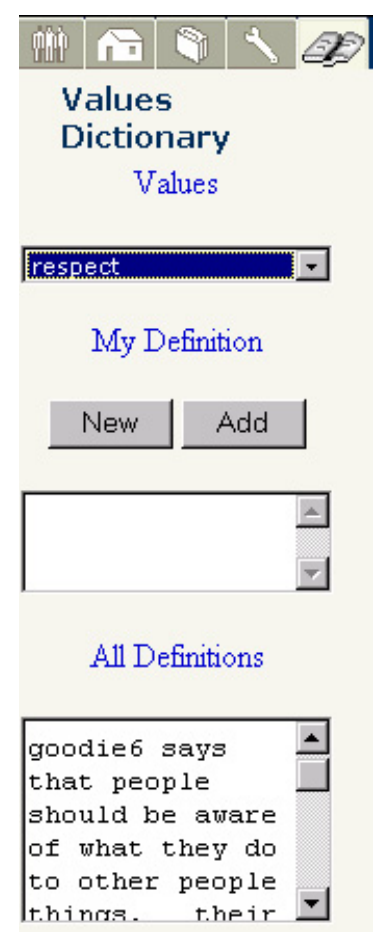

Figure 11: The collaborative values dictionary 


\subsubsection{Conceptual Foundation: Need of a community to develop a sense of self and values}

- A multi-user environment: The rationale behind designing a multi-user environment was to provide a social context that encourages self-exploration and community building. Both introspection and participation are needed in order to learn about identity and develop personal and moral values. A sense of self doesn't develop in a vacuum but through constant interaction with others in a community. As shown by research on moral education presented in section 3.3, only in the context of a community can learners go beyond treating values solely as matters of reflection but also as matters of behavior. Therefore the choice of a multi-user environment that supports the formation of community.

- Multiple modes of interaction: In Zora communication is both synchronous (learners converse with each other via a graphical real-time chat system using both text and gestures) and asynchronous (learners post messages, read and write text stored in their artifacts and the values dictionary). Real-time chat facilitates exchanging points of view in a dynamic way. Communicating through gestures makes the experience more engaging and provides a different channel of expression, particularly of emotions. By communicating with each other kids not only express their sense of self and values, but also learn how to exchange opinions and debate in a respectful way.

- The cases: The notion of a "case" was introduced in Zora in order to help kids ground the on-line conversations in concrete artifacts. A "case" is an object representing an 
event or circumstance to be discussed and agreed upon by the community members. In the same spirit as legal cases, they require community members to take action to resolve them. This kind of participation in a learning environment serves as a model of the larger political community in which the child will participate as an adult. Zora presents new cases as an empty template with a default shape of a green pyramid. Kids can make new cases and personalize them. For example, in Zora's City hall, kids created different kinds of cases. Most dealt with setting up the social organization of the virtual city, such as "I think that people should not change or put things in other peoples rooms. Unless they have permission" or "Anyone should be able to drop anything anywhere, but with a consequence. This should be like breaking a law, punishable by imprisonment of one hour". Other cases were about controversial current events reported in the newspaper ${ }^{6}$. These cases fostered thinking not only about the Zora micro-community but also about society at large. In Zora, the nonstructured discussion of cases is a key element for forming a participatory community.

\section{The pilot workshop}

The goals of the intensive summer workshop, held at the Media Lab, were to find out how young people used Zora to explore their identity while developing a sense of personal and moral values, and to determine how Zora afforded this particular kind of learning.

\footnotetext{
${ }^{6}$ In the workshop reported in this paper I took a child-centered perspective, therefore the only cases to be discussed were those created by the young participants. However, in a different type of experience, where
} 
Participants in the Zora summer workshop were recruited through postings in different emailing lists. Interested candidates had to complete an application form with open-ended questions about their background, including their knowledge and use of computers. They also had to write about themselves and their potential interest in the workshop. The goal of students submitting an application was to obtain a self-selected highly motivated group. It was made explicit to them that the goals of the workshop were "learning about computers as well as exploring issues about youth identity".

I selected a diverse group of 11 kids between ages of 11 and 15 years old to participate in the workshop. The selection process favored diverse cultural and religious backgrounds, gender balance, as well as the quality of the submitted biographies. I did not favor grammatically correct or well-structured stories, but personal and introspective ones. Previous computer experience was not a factor for selection, but participants were required to have access to e-mail.

The selected population for the workshop was diverse: five girls and six boys, two African-American, two Asian American, one Latino, one Iranian and five WhiteAmerican, one Baptist and one Jewish. Six of the participants were inner city kids going to private schools. Selecting a diverse population served two purposes. First, the educational goal of conveying to participants that in order to explore issues of identity and values, different voices need to be represented. Second, to observe if diversity would 
The Journal of the Learning Sciences. Vol 10 N 4. NJ: Lawrence Erlbaum. Pp 365-415

generate interesting discussions when conflict would surface, and how motivated participants would navigate those conflicts.

Eight of the participants came to the Media Lab and three of them worked remotely from their homes and met face-to-face only on the first and last days of the workshop. All participants were subscribed to the workshop mailing list. Parents were also subscribed to a parent's mailing list and were invited, on the last day of the workshop, to an open house. As shown in previous research, engaging parents is important in any learning process, but particularly when exploring issues of identity and values (Okin \& Reich, 1999; Bers \& Urrea, 2000).

An older child, whom I will call Elisa (names of workshop participants have been changed to protect privacy), served as a mentor and helped to informally coordinate the activity. Elisa was only one year older than the oldest of the participants, but she had good social and technical skills and had had previous experience with Zora. Her role in the workshop was to mediate between the kids and myself and act as a peer mentor. Since one of my goals was to observe how kids would use Zora, I did not want to influence them by directly participating in the virtual experience. Elisa became the $12^{\text {th }}$ participant in the workshop, delegating the role of helping with technical issues to the new kids who quickly became the Zora experts.

Each participant worked with a personal computer with Photoshop and the Zora client, as well as a diskette to use with the digital cameras. They were also given a design notebook 
and encouraged to write down ideas, sketches and problems for the workshop's duration. They could take the design notebooks home and document some after thoughts. Throughout the workshop, participants at the Media Lab were videotaped. Kids working from home received the client software and technical support. They also borrowed a digital camera.

The workshop lasted for three weeks. We met three times a week for three hours at the MIT Media Lab. During the first week, we played warm-up games aimed at helping kids get to know each other. Everyday we would take a half hour break for tea and cookies. The idea of the tea was to informally elicit participants to evaluate the experience on a day to day basis. The workshop followed a flexible syllabus that helped Elisa guide the activities (see figure 12).

\begin{tabular}{|c|l|}
\hline Day & \multicolumn{1}{|c|}{ Activities planned in the syllabus } \\
\hline $\mathbf{1}$ & $\begin{array}{l}\text { Filling out a pre-questionnaire, warm-up games, give out design notebooks, 15' Zora demo, } \\
\text { making an avatar (intro to digital camera, Photoshop and Zora's avatar construction kit). }\end{array}$ \\
\hline $\mathbf{2}$ & $\begin{array}{l}\text { Warm-up games, finishing up the personal avatar, making the avatar's profile, visiting an } \\
\text { example of a virtual home, building a personal virtual home. }\end{array}$ \\
\hline $\mathbf{3}$ & $\begin{array}{l}\text { Finishing up the virtual home, looking at the values dictionary and adding definitions, meeting } \\
\text { in City Hall. }\end{array}$ \\
\hline $\mathbf{4}$ & $\begin{array}{l}\text { Visiting each other's virtual homes and giving presents, visiting an example of a temple, } \\
\text { building temples, meeting in City Hall. }\end{array}$ \\
\hline $\mathbf{5}$ & Finishing up the temples, meeting in City Hall. \\
\hline $\mathbf{6}$ & Visiting each other's temples and giving presents, meeting in City Hall. \\
\hline $\mathbf{8}$ & Finishing up virtual homes and temples, meeting in City Hall. \\
\hline
\end{tabular}




\begin{tabular}{|c|l|}
\hline 9 & $\begin{array}{l}\text { Leaving a legacy to future inhabitants of the city, meeting in City Hall, group evaluation, } \\
\text { preparing for the open house, open house for family and friends. }\end{array}$ \\
\hline
\end{tabular}

Figure 12: activities programmed in the syllabus to help the coordinator

Kids worked on their projects at their own pace regardless of the activities planned in the syllabus (see figure 13). As the workshop evolved, kids proposed new activities. For example, they discussed and voted on rules to organize community life. Kids working remotely were able to connect during any other day and time, as well as during the workshop hours.

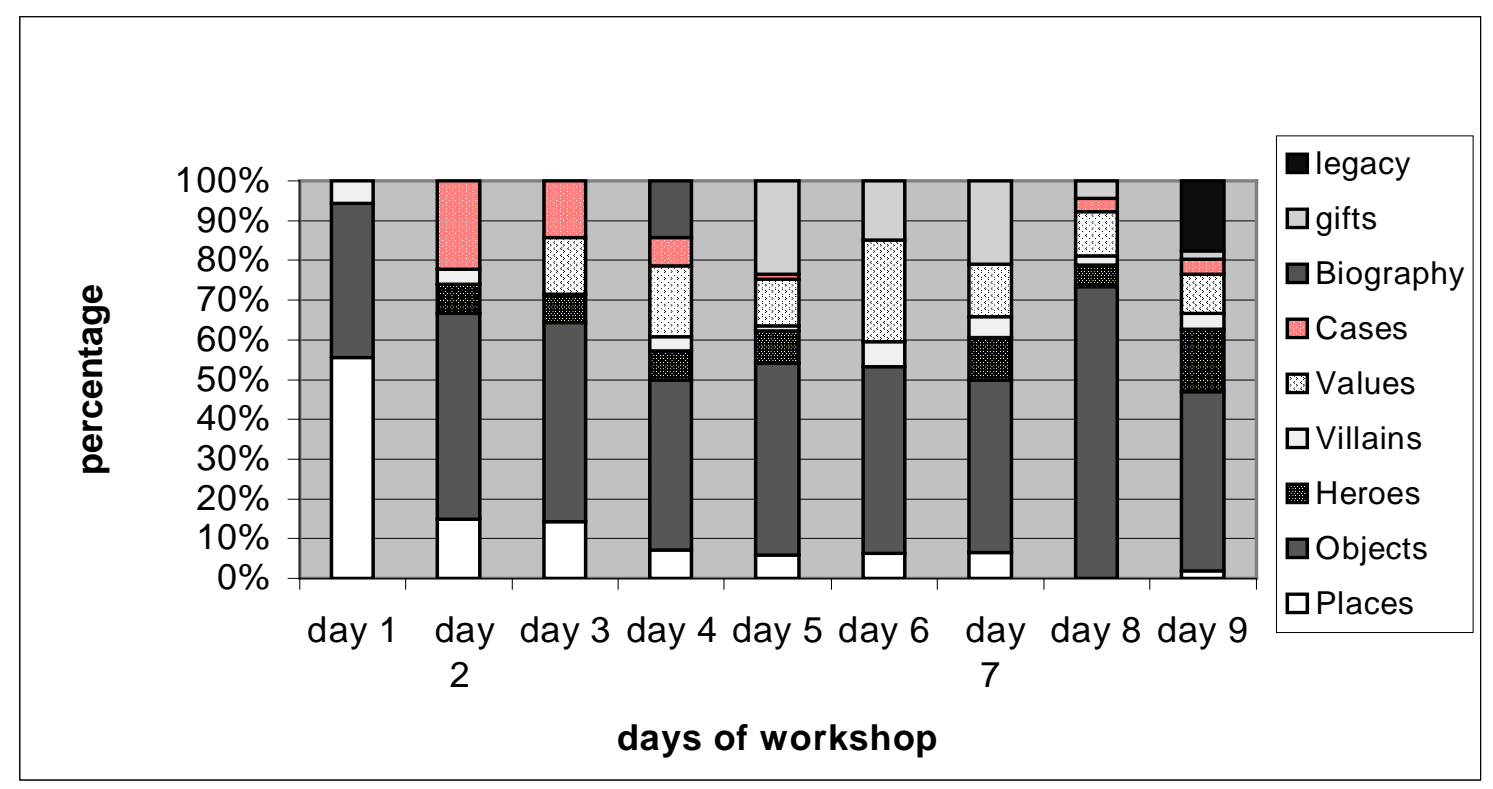

Figure 13: longitudinal distribution of the different creations done by workshop participants ${ }^{7}$

Overall, kids created a total of 33 virtual places divided into 12 personal homes and 19 public temples, such as the Jewish temple, the Sports arena, the Video game room and the Dinosaur hall, and two community centers, the City hall and the Junk shop. Participants

\footnotetext{
${ }^{7}$ A Legacy is a particular kind of object that offers advise to future Zora users about the experience of creating a virtual city. As shown in figure 11, it was a planned activity for the last day of the workshop.
} 
created an average of two temples and one personal home per person, with the exception of one of the kids working at home who created ten virtual places but did not finish any of them.

During the last day of the workshop, every participant left a legacy with advice for future Zora users in the entrance to the city, the Teleport room ${ }^{8}$. Legacies can be grouped into three categories. Those giving advice about technical issues, such as "Using the editor and moving things is hard because you might want to move a picture frame but you move the wall. Be careful". Those giving advice about how to design expressive artifacts and places, such as "Really think about your rooms when you build them. Make sure you personalize them and that the color and everything is really you". And those about how to handle social issues in the community, such as "Zora is all about organization and cooperation... We had many discussions and great thoughts. Zora was great and we learned many things... Organization and cooperation helped us a great deal. To the new user: have fun!".

\subsection{A note on methodology and evaluation methods}

The decision to use Zora in the context of a summer workshop held at MIT, instead of in a classroom or with all of the participants logging in from home was based on a reality. Zora makes special demands on time and technological infrastructure that are not always available in schools and homes in a reliable way. As computers become cheaper and bandwidth for network becomes bigger, this problem might be solved.

\footnotetext{
${ }^{8}$ The teleport room provides direct access to every place in Zora.
} 
The methodology used in the workshop focused exclusively on a child-centered approach to learning. One of the goals of this work was to observe to what extent an identity construction environment with design features informed by theories of identity formation and moral development, such as Zora, would engage kids in exploration of identity and personal and moral values. Because the presence of an adult with background knowledge about this area and who would behave as coach or guide would bias the results, it was consciously avoided.

In terms of evaluating the experience, I used an ethnographic approach with a natural observation method, analysis of system logs, pre and post-questionnaires and a final extended personal interview. In the same spirit as the ethnographer who immerses him or herself in a village to understand how its inhabitants live and think (Geertz, 1973), I immersed myself in the Zora virtual city, before, during and after the workshop, to try to understand how kids used the environment to explore issues of identity and personal and moral values. In order to avoid what Papert calls "technocentric questions", the evaluation was centered on what young people did with Zora and not what Zora did to them (Papert, 1987).

\section{Learning stories}

In this section, I report and analyze how Zora was used and what kids learned by engaging with the system. I focus in four learning stories of projects done by participants in the Zora workshop. These stories do not show the complete range of projects that can happen in Zora. Rather, they are intended to provide a representative sampling of how and what young people learn when they are engaged in using the Zora identity 
The Journal of the Learning Sciences. Vol 10 N 4. NJ: Lawrence Erlbaum. Pp 365-415

construction environment. Each of the following subsections presents a participant's learning experience with one particular aspect of Zora.

\subsection{Virtual autotopographies: spaces for exploring identity}

How did learners explore their sense of identity using Zora? How did they express

Erickson's tension between differentiation from others and integration into a major social group? Young people designed virtual autotopographies, personal and public spaces in which they grouped together aspects of the self.

\subsubsection{Pablo: "you can see that I am Latino"}

Pablo was born in the United States but he describes himself as being from Puerto Rico and Colombia, his parent's homelands. He belongs to a Catholic Church and goes to prayer every week. He likes being in nature and to act in plays at school. He is a very articulate thirteen-year-old. He is funny and witty and has a sweet and kind manner. Pablo is very big for his age and most people think that he is older than he really is. He is very proud of that. A few years ago, Pablo earned a scholarship that enables him to attend a private suburban school. Pablo comes from a low-income family and has to travel far in order to get to school. But he likes it. He says that he feels special and lucky.

During the workshop, Pablo designed a virtual house with different shades of blue, his favorite color. He worked hard to display a careful spatial arrangement of objects. On the right side, the favorite presents given to him by other participants: a map of Colombia and a picture of two puppies. On the left side, at same distance from each other, pictures of his family, his pets, his jewelry and his favorite landscapes (see figure 14). At a surface level, Pablo's virtual home seems almost identical to other homes in popular graphical multi-user environments. But there are several differences. Pablo was 
The Journal of the Learning Sciences. Vol 10 N 4. NJ: Lawrence Erlbaum. Pp 365-415

completely in charge of designing his house. He chose the colors and textures of the walls to give the space its own particular feel. He also made important decisions about what kinds of objects and characters would inhabit it.

Pablo frequently used the term personalization to describe the process of designing his virtual home: "A nice way to personalize it and make it really mine was to put pictures of my family because they really mean a lot to me. Choosing which picture to put was a personal thing. I mean, it was a way to think about the things and people I really care about... I don't mind if other people take a look at those pictures, but I put them up for myself."

While designing his home and choosing meaningful objects, Pablo engaged in a process of introspection. In Pablo's virtual home there is no furniture or objects that serve solely a physical function. Instead they each serve a symbolic function. They represent aspects of Pablo's identity. Pablo's home is a virtual autotopography, a spatial representation of identity composed by symbolically significant objects. Virtual autotopographies give materiality and concreteness to intangible aspects of the self such as Pablo being Latino, his emotional relationship with his family back in Colombia, and his love for nature and the color blue. 


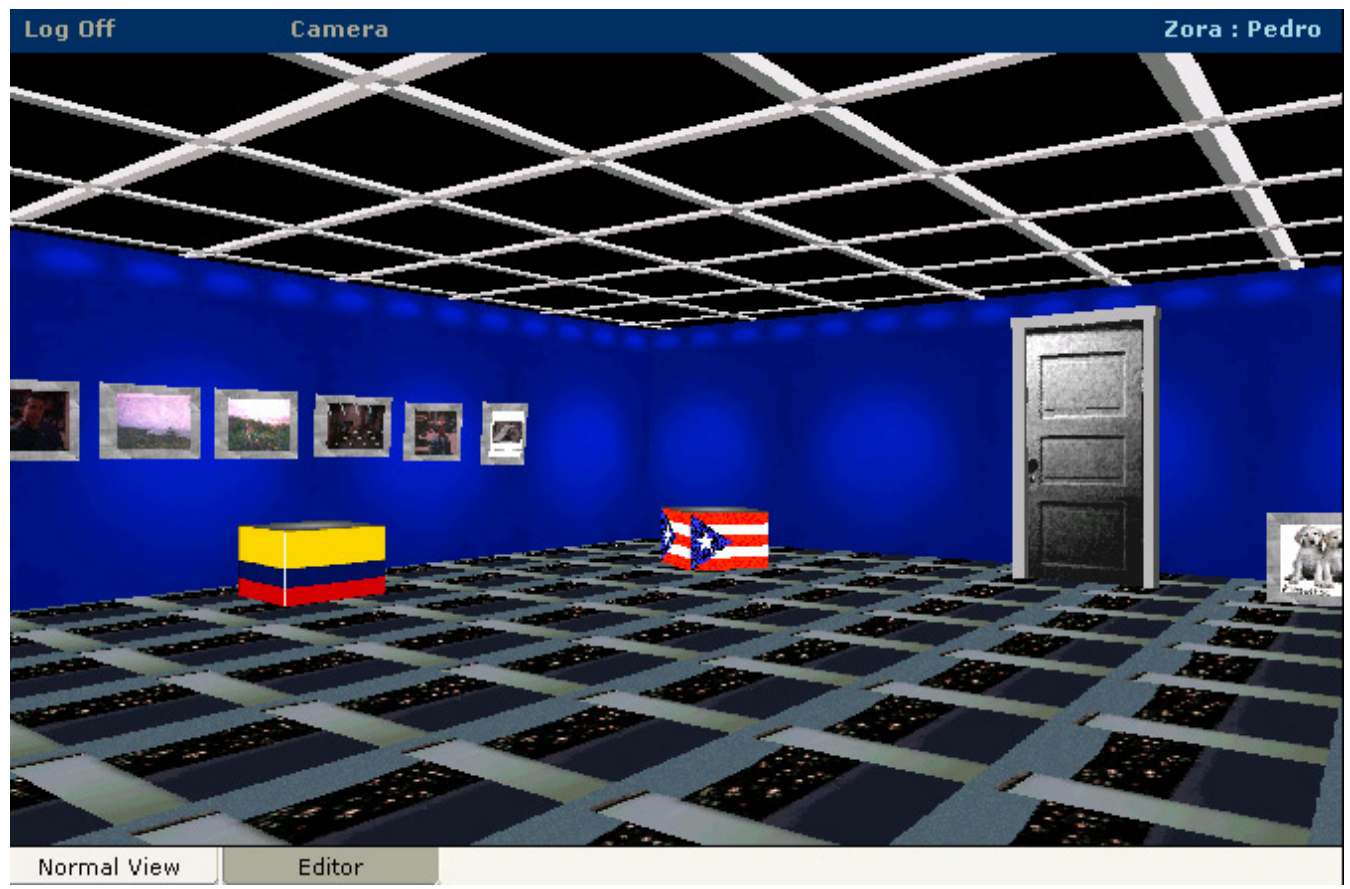

Figure 14: Pablo's virtual home with blue walls and ceiling

Pablo worked hard in "personalizing" his virtual home. He spent the duration of the workshop refining it, trying different matching colors and adding and deleting objects. Pablo treated every object, not as a unit by itself, but as a component of a major whole. He was as interested in the relationship between objects as in the objects themselves. Pablo thought about the objects in his virtual home in terms of elements of a coherent system (i.e. his identity) and not in isolation. For example, he put flags from both Puerto Rico and Colombia, his parents' homelands, bracketing pictures of himself with his relatives. He moved stuff around many times and calculated exact distances between flags instead of the "looks good" method. Pablo used the spatial location of objects to amplify or mirror an aspect of his identity, his cultural heritage, that he also chose to highlight while creating his avatar's textual profile: "My name is Pablo, I'm 13 and live in 
The Journal of the Learning Sciences. Vol 10 N 4. NJ: Lawrence Erlbaum. Pp 365-415

Boston. My dad was born in Puerto Rico, and my mom is Colombian. Even though I was born in Boston I consider myself to be either Puerto Rican or Colombian."

Over time Pablo re-configured his virtual autotopography according to his evolving perceptions about identity. For example, by the third week of the workshop he realized that he had put too many singers in his virtual home. So he decided to make the "Salsa and Merengue temple" and move them over there. In Zora, virtual temples are shared public spaces that represent cultural traditions or group interests. In contrast with personal homes, which are private collections of objects, temples are public groupings of objects that share a specific content or theme. Virtual temples are extended autotopographies that engage kids in looking outward and finding cultures and subcultures they identify with. By creating the "Salsa and Merengue temple", Pablo's hope was that others who also shared a taste for that kind of music would help him populate it. He compiled a list of his favorite 34 singers and musicians, whom, at first sight, were all Latinos, just like him.

As Pablo used the Internet to do research about them, he realized that it wasn't clear what the word Latino meant. As he shared in one of the tea breaks, the hardest task for him was deciding which singers were to be defined as Latino. His first attempt was based on the language they use to sing. However this led him to the problem of how to categorize some of them who do not sing in Spanish but are originally from Latin America and others who sing in Spanish but are not Latino. At this point, Pablo asked the question "what does it mean to be Latino?" and explored an aspect of his identity that particularly 
The Journal of the Learning Sciences. Vol 10 N 4. NJ: Lawrence Erlbaum. Pp 365-415

troubles him. As he later shared during one of the virtual City hall meetings, Pablo goes to a private school where he is part of a Latino minority and he struggles hard with issues of segregation.

During the final interview, when Pablo was asked what he learned during the workshop, he said, "I don't feel that I learned particular skills, although I learned how to use Photoshop, Zora, and the computer better. But what I learned most was how to think about different things in different ways and how to express myself a little bit better through objects like the flags and everything I put in my room. If you go there, you can really tell who I am, you can see it. I guess I learned how objects can say a lot about a person" [emphasis his].

\subsubsection{Elisa: the personal meaning of Judaism}

Elisa, the mentor, is the daughter of a rabbi, goes to a Jewish school and much of her identity is linked to Judaism. She lives in a wealthy part of town and is very proud of her Jewish heritage. She wears Jewish symbols around her neck and likes to read and write in Hebrew. She is very driven, independent, and outgoing. She loves to talk about herself and has many friends. She has strong opinions about what is good and bad and she is not shy to share them with others. Elisa's role in the workshop was to be a peer mentor. She followed a daily syllabus but she knew that kids were free to ignore her guidelines. She was in charge of helping kids with technical difficulties and make them feel comfortable with each other. She started out by building a virtual temple instead of a personal home. She wasn't the only one to do so. Other kids, like Michael, also built first a temple, a TV room with his favorite shows. Elisa created a Jewish temple containing objects, such as a 
Jewish prayer book, a picture with her name written in Hebrew, and an Israeli flag, as well as heroes like Steven Spielberg and her dad (see figure 15). Elisa's learning story shows how a mentor engages in a personally meaningful learning experience.

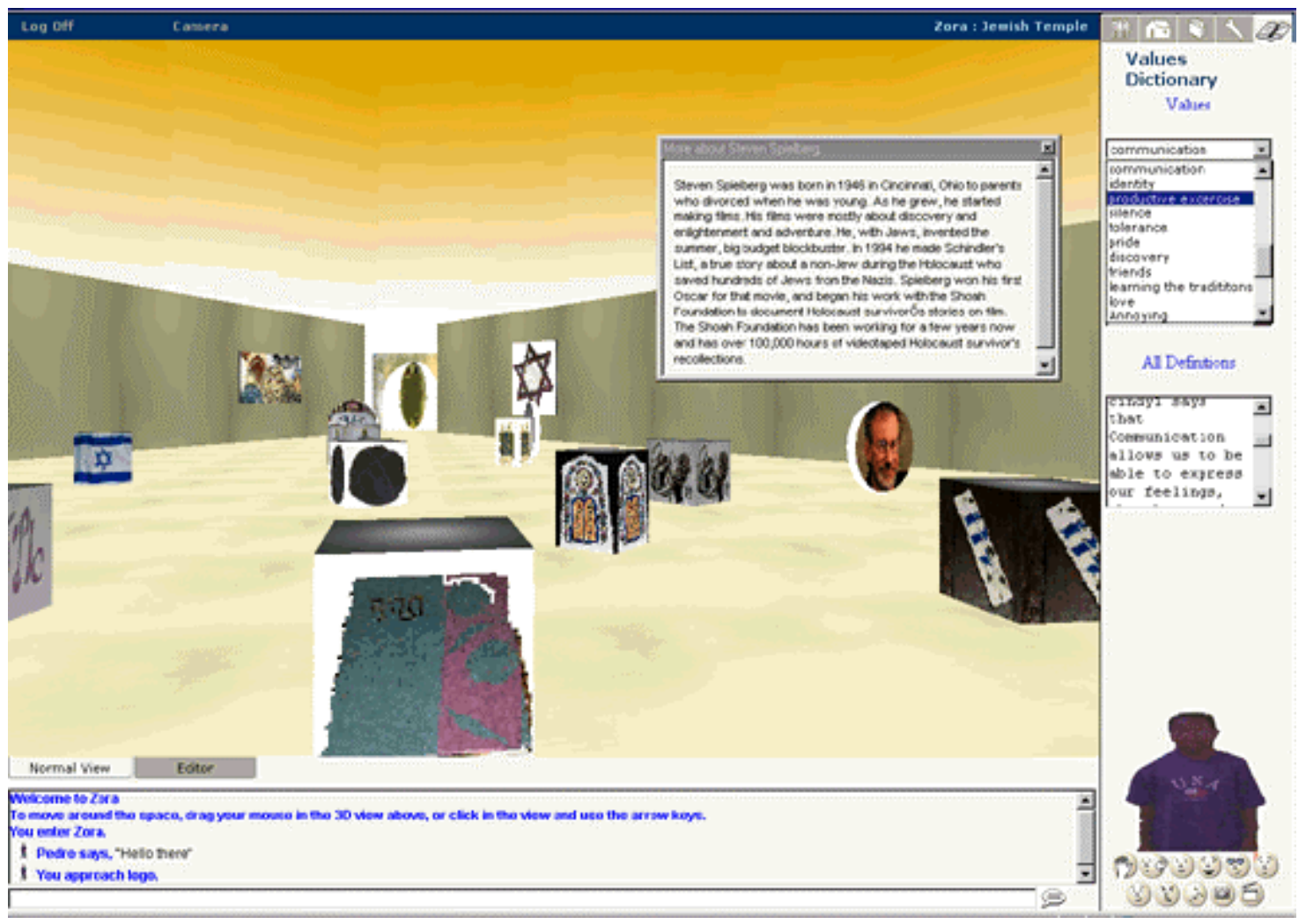

Figure 15: the Jewish temple built by Elisa

In Elisa's Jewish temple, every single object has personal stories attached to it as well as descriptions aimed at teaching others about Judaism. For example, the kippah has the following description "Leather or cloth skullcap worn on the head to both show and feel closer connection to God through the body" and tells the following story "I live in the USA, and so I don't normally see Jews just walking down the street in a non-Jewish environment. Even if I did see one, I wouldn't know because Jews look the same as everyone else. That's why I love when I see someone in a kippah. They enable me to know 
The Journal of the Learning Sciences. Vol 10 N 4. NJ: Lawrence Erlbaum. Pp 365-415

if they are Jewish just by looking at them... whenever I see random people wearing kippot Ifeel closer to them. I know that being Jewish is just as important for them as it is to me." While building her Jewish temple, Elisa did research about what kinds of objects best express Judaism, but especially her particular vision of it. Elisa's learning experience went beyond the typical project-based learning experiences in which students are asked to do extensive research on a topic but sometimes miss a deeper personal connection to the subject (Barron et al, 1998). While designing her Jewish temple Elisa learned more about Judaism, but even more important, she was able to reflect about what Judaism means for her. Zora's design helped her in this process by inviting her to associate personal values and stories to objects, and not only standard information.

Both Pablo and Elisa engaged in a process of self-reflection while designing their virtual autotopographies. This introspective exploration is similar to the kind of "working through" issues of identity that Sherry Turkle, borrowing from Erikson, describes as a moratorium, or a time of constant experimentation and reflection in the adolescent's life. The process of self-reflection that Elisa and Pablo engaged in has some resemblance to what happens during therapeutic interventions and meditative or religious experiences. However, during the experience with Zora, the products of self-reflection became tangible, dynamic and manipulable. The collection of objects and stories in Pablo's and Elisa's virtual autotopographies represent personal identity as a complex construction composed by different aspects of themselves. In general, this constructionist notion of identity is not part of the school curriculum and only becomes available in specific college level courses. However, as shown by Erikson's work, it is early on, during 
The Journal of the Learning Sciences. Vol 10 N 4. NJ: Lawrence Erlbaum. Pp 365-415

adolescence, that kids engage in the quest for identity. Therefore it is at this critical stage of their life cycle that they would strongly benefit from having a rich set of conceptual and material tools to explore identity.

\subsection{A participatory micro-community in Zora's City Hall}

In order to develop a sense of identity and personal and moral values, participation in a community is needed. On the one hand, the dynamic process of identifying with and differentiating from others is essential to form a coherent sense of self. As Erik Erikson points out, "no ego can develop outside of social processes that offer workable prototypes and roles" (Erikson, 1950). On the other hand, extensive research suggests that the involvement in participatory democracy, social institutions, group decisionmaking and self-government are critical in shaping individual's moral development (Kohlberg, 1985).

Zora provided the opportunity to develop a participatory micro-community, a safe space in which to experiment with ways of thinking and behaving needed to function in a community. In the experience described in this paper, the micro-community is different from traditional virtual communities, such as those created in chats and MUD's, because individuals have both on-line and real-time face to face interactions. How did learners create a micro-community in Zora? How did they participate in its self-government? What are the differences and similarities to the model of a face-to-face just community proposed by Kohlberg? These are some of the issues that I will address in this learning story. 
The Journal of the Learning Sciences. Vol 10 N 4. NJ: Lawrence Erlbaum. Pp 365-415

Learners created a virtual City Hall as a space for the community to gather and talk about issues relevant to its social organization. The Zora system was seeded with a template of a City Hall, which they decided to use. They also decided that the cases that community members wanted to discuss with others needed to be placed there for later discussion. For example, during the second day of the workshop, kids discovered the need to create laws to make living in Zora easier. This realization happened as learners started to try out different Zora features and test its technical limits. For example, they created huge objects and left them in inadequate virtual places, they learned how to distort the look of personal avatars and how to change the size of other people's personal homes. In contrast with other experiences of just-community in education, the idea of creating laws emerged in a natural way, as a need of the community, and not as a suggestion from an external agent, such as teacher or facilitator. In the first City hall virtual meeting a city mayor was elected and took charge of coordinating the writing of the rules of Zora. Participants placed cases that they thought needed to become a rule. Kids experimented with different on-line voting systems, such as "press 1 if you agree" or "stand on the left side of the room if you disagree”, but they had a hard time organizing themselves so everyone was heard and consensus was reached. This was due, in part, to their lack of familiarity with on-line synchronous communication, and in part, with their inexperience organizing themselves without top-down intervention.

After a long discussion with many disruptions, they agreed on some basic rules: "no putting things in people's personal rooms", "no warping people or their things", "set the properties of the objects placed in public spaces so others can clone them", "people can 
The Journal of the Learning Sciences. Vol 10 N 4. NJ: Lawrence Erlbaum. Pp 365-415

make their own rules for their own rooms but it must be clear", " the junk room can never be too full", "fess up to what you do", and "there will be no jail".

During the following days kids continued meeting in the City hall and reviewing the new cases placed there. For example, there was a heated discussion about the "punishment" case created by fifteen year old Nino, which said "there should be physical punishment to rule breakers."

Nino's punishment case wasn't accepted to become a law by the rest of the kids who thought they idea was "ridiculous and absurd in a peaceful city". Some of the kids proposed community service as a form of punishment, while others advocated for locking people up in a jail. They spent a long time, mostly face-to-face, discussing how to technically implement a virtual jail from where avatars couldn't escape. They considered the possibility of having a guard in charge, but no one wanted that role because "it is too boring to always stay in the same place and go after people”. Finally consensus was reached and a law was created: "Punishment for breaking a rule is to write a value in the dictionary".

Another case that didn't make it into a law was about the creation of a stripping bar. This case originated as a result of one of the kids finding a cartoon character, called Theo, that when clicked on the posing gesture would strip. Although there were no body parts exposed, the gesture of the character was clear at conveying the idea of stripping. The stripping issue kept being discussed all along the workshop, maybe due to the fact that kids were in the teens, an age in which talking about sex is particularly appealing. 
However, the stripping bar was never created and stripping was outlawed. Zora

community members chose Theo as both a hero and villain. The value stripping, was given the definition "the freedom of pure and care free expression". Following is an extract from the system log on stripping:

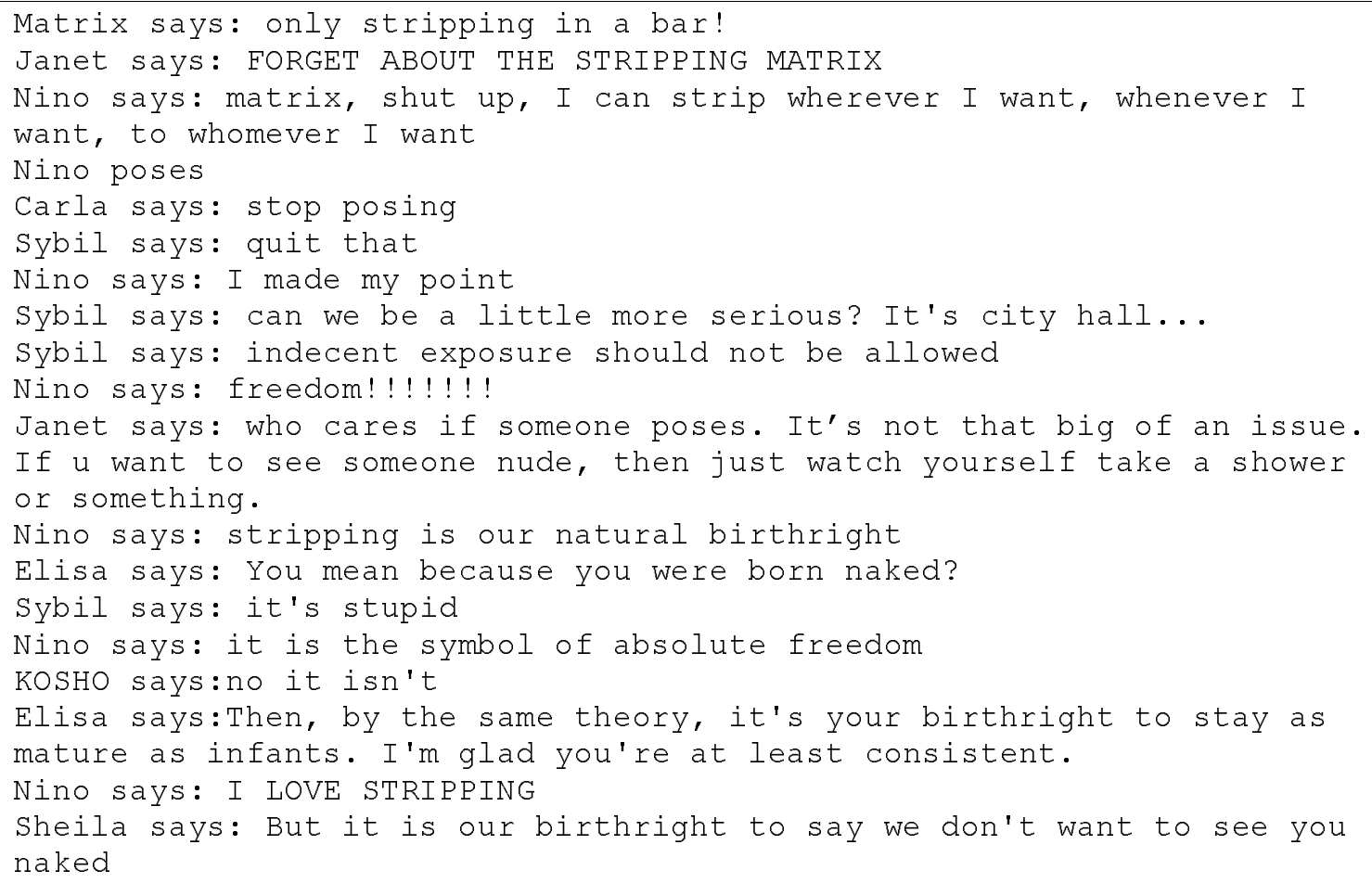

On the one hand, the virtual City hall provided a public forum for participatory

democracy and decision-making about authentic dilemmas faced by the Zora community, such as the creation of laws, a jail or a stripping bar. On the other hand, it provided a safe space to voice opinions and discuss moral dilemmas faced by society at large. For example, during the second week of the workshop, Elisa, who built the virtual Jewish temple, placed in the City hall a case with a web link to a news article about a shooting in a Jewish Community Center in L.A that had happened the day before. She attached to it the value "tolerance" and defined it as "Tolerance is something that everybody needs in relation to other people or nobody would be able to get along with anyone else. We 


\section{to discuss the news.}

Elisa says: It was very scary. I read the article and one of the things the man who committed this act said he wanted to remind people that all Jews should be killed. That sent serious shivers down my spine.

KOSHO says: Nazis. A leader tells them that others are the cause of all their problems.

Pablo says: some people are just looking for someone to blame.

Janet says: people are gonna feel the way they want to feel and no one can really change their minds

Pablo says: they are entitled to their opinions but it's their actions that need to be stopped

Elisa says: Janet, do you really think that? No one can change their minds? And if it's true that we can't change their minds, should we do something to limit their actions?

Pablo says: there isn't anything we can do.

Nino says: this guy should be dragged out and flayed alive

KOSHO says: you just can't fix a wrong with a wrong

Janet. says: yeah violence is never the answer

Nino says: if anybody deserves the death penalty, he does

Pablo says: but I think no one deserves the death penalty

Carla says: he should just have life in jail

Sheila says: He shouldn't be shot but helped, I really don't know how, but he just needs a way to get familiar with other cultures

Nino says: that's not going to help. Death penalty.

Pablo says: we don't have the authority to take a person's life. Death penalty is still not justified

Sheila says: I think by killing him we show that we have given up and the only way to solve things is to kill somebody, and I know that is not right

Matrix says: I read an editorial that said people should just be put in jail for life because, believe it or not, the death penalty cost more than letting him live for the rest of his life(30 yrs.)

Elisa says: answer my questions, should anyone who kills be killed? Or does intent matter? And if intent matters does it matter more or less than the result of the action?

Nino says: intent and result both matter

Elisa says: And once he is killed, assuming he is, what would be the repercussions of that? Would his family go after the government?

Would he become a Neo-Nazi martyr?

Janet says: maybe there should be a boot camp for people like this Pablo says: it wouldn't really work. The only prevention is at home. people need to be brought up knowing discrimination is wrong

Sheila says: I think we can't do that much for adults, but the kids in school I know we can do a lot, so I think we should try to concentrate on making sure they know that this stuff is wrong

Janet says: yeah we should try to prevent

Pablo says: the only place is at home

Elisa says: I'm thinking that if it doesn't exist in the home, school

won't help, but only home won't be as good as home and school.

Pablo says: teachers don't have nearly enough influence as the parents 
The Journal of the Learning Sciences. Vol 10 N 4. NJ: Lawrence Erlbaum. Pp 365-415

As a result of this conversation Eric, one of the youngest kids in the workshop, who was very quiet "listening" but did not participate in the on-line conversation made the "Everyone's temple". He described it as a space for "all the cultures and religions to get along”. Other kids who had already started a temple made a special effort to put more objects and characters to teach others about its content. For example, Sheila further developed the Southern Baptist church. She put God as a hero, and the devil as a villain, and wrote stories to convey her point of view about them. Also, kids who had not yet put any cultural object in their rooms or temples, added flags to them. For example, Janet put a flag from her homeland Nigeria and Kosho from his mother's home, Iran. Kousho attached the value "identity" to his flag and defined it as "I say that identity tells people who I am and what culture I belong to."

In Kohlberg's just community approach, students and teachers also engage in conversations about dilemmas and controversial issues, similar to the ones described above. However, members can make decisions about all aspects of the community life, except curriculum decisions. This is a big difference with the Zora experience. As shown by the examples above, community members do not follow an already established curriculum specifying the activities they should engage in. They have the power to decide what kind of projects they would work on. Another difference with Kohlberg's approach is that Zora makes it easy for learners to observe the connections between what is said in the on-line conversations (i.e. discussion about discrimination) and what is done in the virtual city (i.e. creating the "Everyone's temple"). An environment that offers the possibility of observing the relationship between saying and doing is useful because in 
issues of identity and values, concrete actions matter as much as analytical thinking (Blasi,1983; 1984). In the real world, instead, taking action would involve a long-term process and, because of the feedback loop, it would be hard for young kids to be in complete control of an authentic experience.

For most of the workshop participants (except for two who attend parochial schools and one who goes to a particularly progressive private school) this was the first time they encountered an atmosphere where they could have conversations about controversial issues in an open way. In the final interview, Sheila said: "The City hall was a place to freely voice your opinions and I had a lot to say because in my school we don't talk about this kind of current events and if we do it is only in separate clubs". Following is an extract from the log:

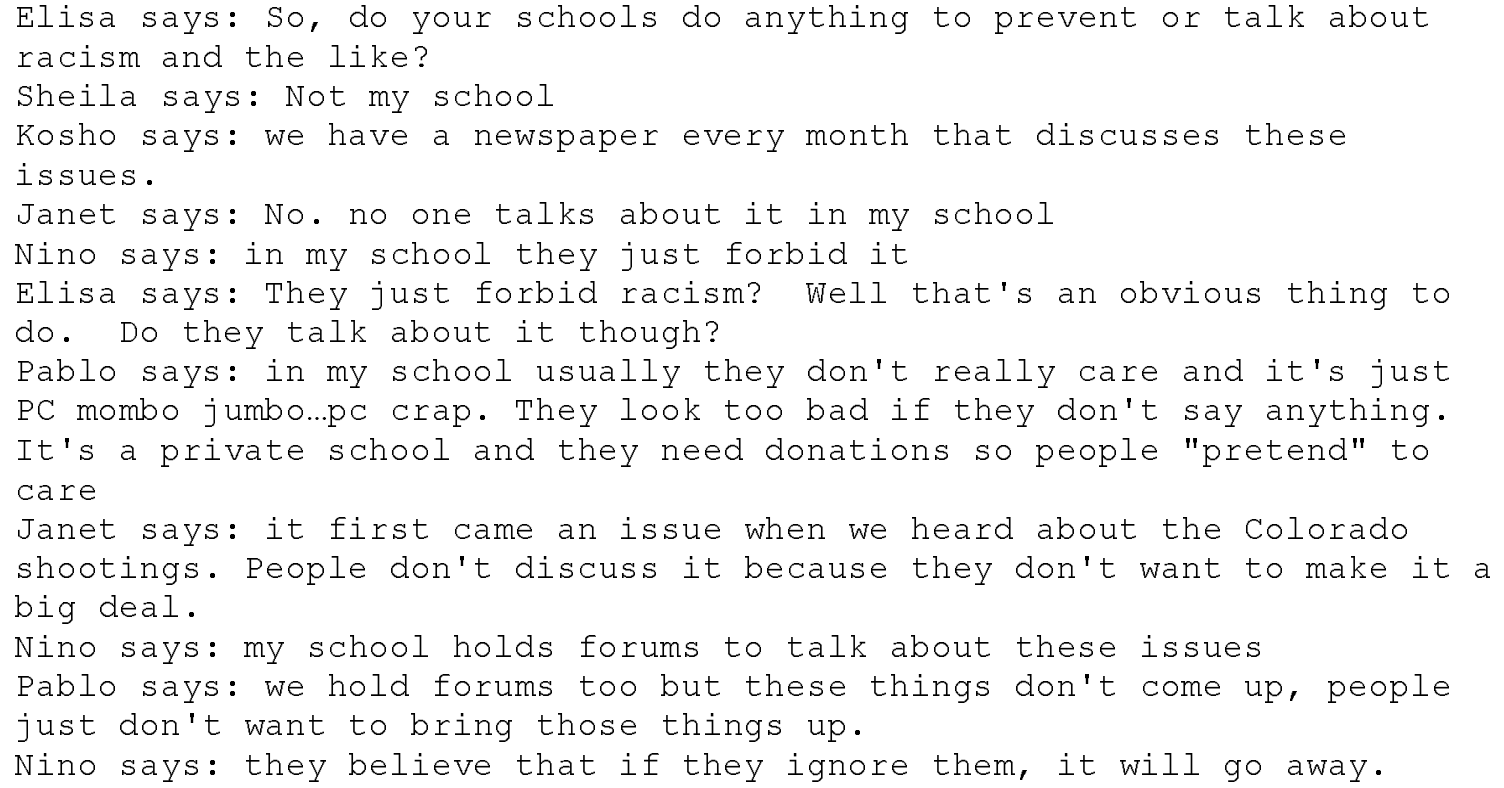

As research by Erickson has shown, young people need spaces to talk about controversial issues and work through different explanations and points of views. There is an important 
body of research on computer supported spaces to foster discussion and reflection. Some of this work is aimed at supporting discussion about science work (Songer, 1996; Scardamalia \& Bereiter, 1994; Pea et al. 1994; Edelson, 1999), while other hopes to engage students in case-based moral reasoning about current ethical choices (Cavalier, 1996; 1998). However, none of this work tries to understand how to explicitly design networked technologies to support discussion and reflection about personal and moral values in relationship to identity in the way that Zora does.

The discussions happening in the City hall offered an opportunity to engage in thoughtful discussion with people with different opinions and who make explicit their values through their virtual creations. "It was the first time I had this conversation [about death penalty] with someone who thought in such a different way than I do. It was weird because I didn't know I felt so strongly against it, but because Nino felt so strongly in favor of it, it forced me to think really hard about what my real thoughts were." Pablo stressed the fact that in a face to face conversation they probably wouldn't be able to discuss this with the same level of "seriousness". As soon as the different opinions became clear they would switch to a more playful tone in order to avoid confrontation. However, it is precisely the open confrontation, in a respectful way, which leads to developing better ways of thinking about controversial issues and understanding them from others' perspectives. At the same time, by engaging in dialogue about their inner worlds, kids were able to learn about themselves and others and share common concerns.

Elisa says: If your school Janet, started seriously working on race relations, it would embarrass you? That's interesting. 


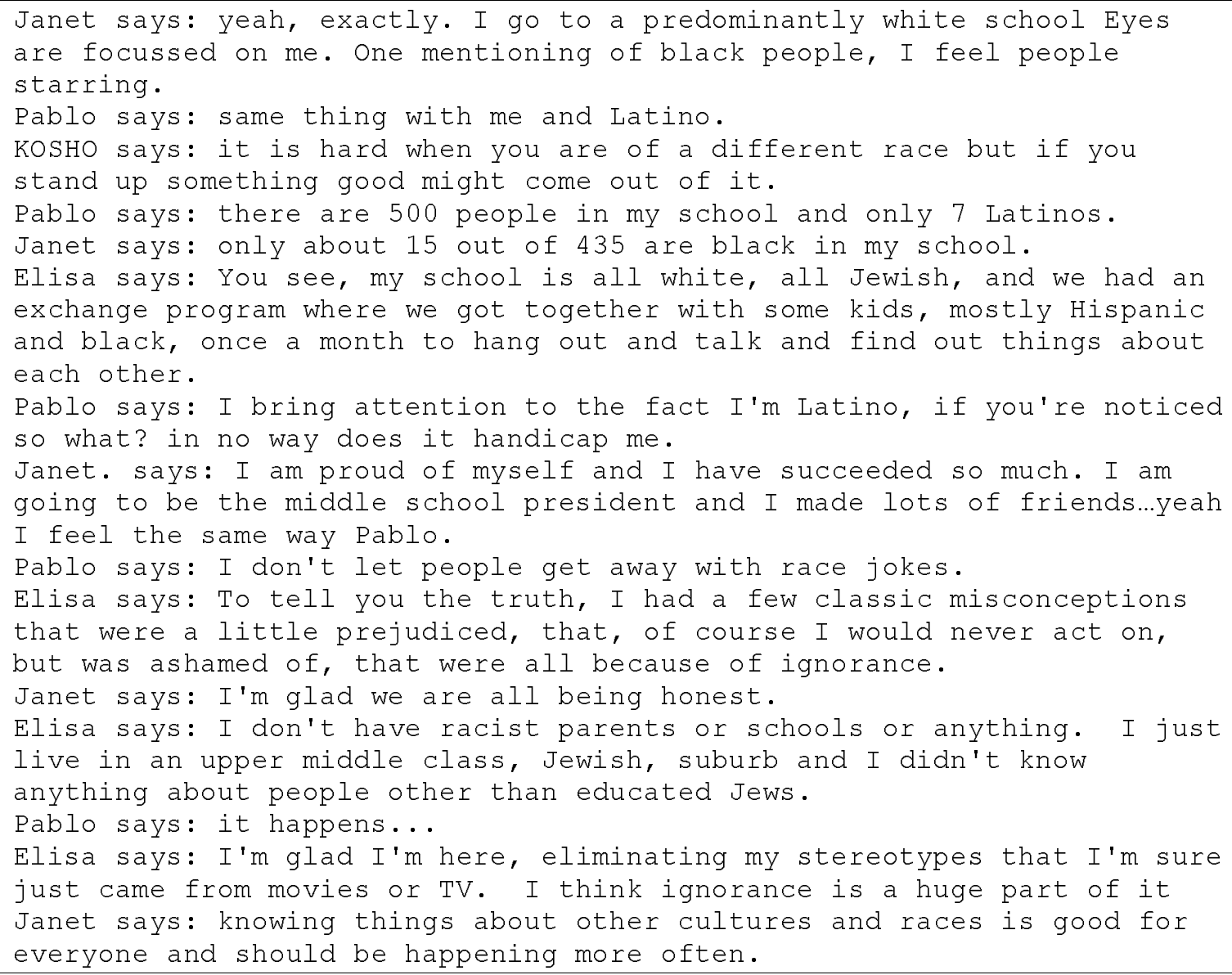

According to most of the workshop participants, being on-line helped them to discuss

certain issues in a deep way. During the final interview Janet, a 14 year-old African

American, reflected upon her experience: "I go to a white school and when they talk

about racism or stuff like that I am embarrassed and I feel all the eyes on me, but in City

hall it was easier because I could talk freely without feeling everyone starring at me." It

is confusing, at first, to understand what Janet meant, particularly because her avatar

displayed a picture of herself and she was physically sitting next to everyone else during

the workshop. Why didn't she feel all the eyes starring at her? I believe there were three

factors. First, Janet could type, instead of talk. This helped her distance herself from the

ideas and express them without feeling observed by her peers. Second, the avatar, 
The Journal of the Learning Sciences. Vol 10 N 4. NJ: Lawrence Erlbaum. Pp 365-415

although it had her picture and name, served the function of an alter ego. Third, Janet knew that Zora was a space explicitly designed to talk openly about these issues and she felt free to express herself because everyone else was also doing it.

These kinds of conversations started on line and were later carried off-line. Video analysis of face to face interactions showed how kids engaged in thoughtful discussion about current controversial issues, such as censorship on a popular movie, during the tea breaks. I believe that having those conversations would have been much harder if kids hadn't had the chance to have the on-line experience first, which allowed them to distance themselves from the ideas and get to know each other in a non ego-threatening environment. Participatory micro-communities, by providing a safe virtual on-line environment, promoted face to face dialogue.

\subsection{Values as aspects of identity: concrete and abstract explorations}

How did learners explore the relationship between personal and moral values and identity while using Zora? What are Zora's design affordances that make this kind of learning possible? What is unique about Zora's approach to help kids understand the relationship between values and identity? These are some of the issues I will address in this section.

Research on values education has focused on the relationship between values and reasoning (Lipman; 1988; Kohlberg, 1976), values and personal views (Chazan, 1985; Raths, Harmin \& Simon, 1978), values and narrative (Tappan \& Brown, 1989; Jhonson, 1993) values and faith (Fowler 1981; Chazan, 1985) values and actions (Blasi,1983) and values and moral identity (Blasi, 1984; Coles, 1986). The research presented in this 
The Journal of the Learning Sciences. Vol 10 N 4. NJ: Lawrence Erlbaum. Pp 365-415

paper extends these approaches by encouraging kids to grapple with the relationship between values and identity.

The relationship between questions such as "who am I" and "what are the values I hold and cherish" is not always easy to address because it is frequently taken for granted or assumed. Therefore, two design decisions were made to help young people explore this relationship in a tangible and concrete way: First, in Zora learners can create objects that evoke aspects of the self. In the spirit of the object-oriented paradigm, they can define these objects with attributes. These attributes are narrative-based, meaning that they tell stories about the particular meaning that learners assign to the objects. Values are also attributes of these objects. And since the objects are meant to evoke aspects of the self, the values associated to them also convey what is most important for the individual. Therefore, when creating these values, learners are explicitly engaged in thinking about the relationship between identity and personal or moral values. Second, this relationship becomes salient by the choices made at the Zora's interface level, which makes it clear that every object is associated with a value attribute.

Zora's design afforded approaching values with a plurality of thinking and learning styles, as shown by the following experiences by Elisa and Sybil. For example, Elisa chose the value "community" and associated it to a picture of her school year book. Here is her definition: “At the New Jewish High School I don't just have teachers and classmates, everyone is friends. I hang out in the office with the staff or in the lounge with my peers. Whenever anyone has a problem, there is someone to whom we can go for help. That is 
The Journal of the Learning Sciences. Vol 10 N 4. NJ: Lawrence Erlbaum. Pp 365-415

community." Elisa's definition is grounded in the concrete object (the yearbook) that represents a personal experience that is an important aspect of Elisa's identity (belonging to the school community).

In contrast, Sybil created the value "community" as a stand-alone value in the values dictionary and defined it as: “... a group of people in a certain place in which everyone cares for each other." She did not associate it with any object in Zora. This definition of community is not anchored to any particular community, therefore its conceptualization is abstract and seeks to be universal. None of these two definitions is better than the other. The difference lies in the kind of thinking process that both Elisa and Sybil engaged in while creating them.

As shown by these two examples, Zora's design supports two very different ways to learn about personal and moral values. One, as shown by Sybil's definition of community, affords thinking about values as repositories of prescribed beliefs or normative universal principles. This is supported by the design feature of the collaborative values dictionary. This approach is typified by abstract definitions. In order to create a new value and its definition in the dictionary, learners think about values as universal principles, disassociating them from any specific context or object in the virtual world ${ }^{9}$. This abstract approach to values is not always conducive to thinking about the relationship between values and identity. However, it is the most common found in educational interventions where the use of the Socratic method of discussion about moral dilemmas 
abound (Lipman, 1988). This abstract approach tends to engage children in thinking about values as a hierarchical pyramid in which the most important values are at the top and can be accessed by logical reasoning.

A different approach to values is represented by Eliza's definition of community. Instead of a universal definition, Elisa wrote about a very concrete case of community (her own school) and represented it with a very concrete object (the yearbook). This way of thinking about values is supported by Zora's design: objects are defined in terms of their behaviors and attributes, of which values are one. Therefore, when a child designs an object, she also has to think about the values that the object conveys and its relationship to her personal identity. During the final interview, when I asked fifteen year old Nino what he learned during the workshop he said: “...how to see values in things... because usually when I see something I just see it, I really don't think about it...this opened my eyes. For example, before I didn't think that there was much value in my Dave Matthew's poster or a picture of me fishing... I didn't think about values at all. By attaching values to things you realize what your values are and you also make other people more likely to know you better. Right now when I see something, somehow I wonder what values it has, and what certain people think its values are."

Most of the kids who worked on Zora chose this concrete way of approaching values (i.e. grounding them and their definitions in objects), instead of the abstract approach (i.e. entering values and definitions directly into the values dictionary). Janet's comment in the

\footnotetext{
${ }^{9}$ It is interesting to note that participants considered this abstract approach as a punishment. As shown earlier, writing a value in the dictionary was a way that the Zora community members chose to penalize bad
} 
The Journal of the Learning Sciences. Vol 10 N 4. NJ: Lawrence Erlbaum. Pp 365-415

post-interview is representative of most participants' opinions: "When I write values for my objects Ifeel like I can express my feelings and it is a way to see what is going through my mind. I usually don't talk about values and don't think much about them. For example I wrote down something about love and I realized wow! I am really into this but I didn't know because I don't talk about it...so there was something new for me. When I wrote the values is when I learned a lot more about myself".

Zora users create virtual autotopographies populated by many objects and their associated values. These autotopographies can be visualized as a dynamic network in which a diversity of values interact with each other. These do not always form a coherent value system but a collection of diverse values that, because they are grounded on very different experiences, might be in conflict with each other. This view provides a different alternative to think about values as a hierarchical pyramid in which values are organized according to universal ethical principles.

This realization did not happen overnight but evolved over time, as children created more complex autotopographies. For example, During the workshop Nino first struggled very hard to understand what are values, in general, and why Zora's design "forced" him to specify values as attributes of objects. He said: "At the beginning my mind would drop to a blank because I usually don't think about values or my values. But since I had to write down the values of objects that I put in my room, it forced me to think deep down inside to see what this actually means to me." For him, as well as for most of the workshop participants, the process of thinking about values in concrete ways turned out to be a

behavior. 
The Journal of the Learning Sciences. Vol 10 N 4. NJ: Lawrence Erlbaum. Pp 365-415

difficult learning experience, even harder than creating abstract definitions in the value dictionary. However, it was perceived to be a more enjoyable task. While treating values in an abstract way led to the repetition of commonly accepted definitions without much thinking about the complexity of their meaning, and was seen as a punishment, the concrete approach required kids to think hard about the connection between the abstract principle and its personal meaning.

As shown in this section, the Zora identity construction environment supported the exploration of values in both an abstract and concrete way. The design and manipulation of computational objects with values attributes provided a unique opportunity for kids to think about the relationship between values and their identity.

\section{Lessons learned: revisiting the design principles}

I started this paper by distinguishing six design principles that make identity construction environments powerful tools to engage learners in the exploration of identity and values, in a hands-on, constructionist way. In this section I reflect on those principles, and summarize lessons learned about identity construction environments while observing the summer workshop participants using Zora.

\section{Identity Construction Environments are purposefully designed to help young} people learn about their identity, particularly personal and moral values. As shown in the learning stories presented in section 6, Zora's design enabled the workshop participants to explore these issues by creating a virtual city. However, Zora's design was not enough to make a successful learning experience. Other factors also had a positive influence: the role of Elisa, the facilitator, who worked as a peer and who also explored issues of identity and values while participating in the 
The Journal of the Learning Sciences. Vol 10 N 4. NJ: Lawrence Erlbaum. Pp 365-415

workshop; the presence of a flexible syllabus that provided Elisa with guidelines for activities; the immersive nature of the workshop, that allowed kids to engage in their projects for long periods of time; the co-existence of both on-line and face to face conversations; and the fact that workshop participants were self-selected, highly motivated, and went through an application process, namely they all wanted to be there.

\section{Identity construction environments are designed upon a theoretical model that} understands identity as a complex and dynamic construction composed by conflicting values. This model informed Zora's design by providing a structure for kids to create a virtual home, or autotopography, populated by collections of different objects and characters representing aspects of a complex evolving self. As shown in the learning stories presented in section 6.1, the virtual homes evolved and dynamically changed as learners' developed different ways of understanding their identity through interactions with others community members. For example, Pablo populated his virtual home, at first, with different objects conveying his Latino origin. He also created a Salsa and Merengue temple. After engaging in an on-line conversation about racism and sharing his feelings about being a minority with other kids, particularly Janet, an African American girl, he further explored what it meant for him to be Latino. As Pablo's perception of who he is and what are his cherished values evolved, he refined his virtual home and temple by adding more objects and creating more complex stories.

\section{Identity construction environments afford opportunities for learners to engage} in the design of computational objects. In Zora, these objects are "tangible" 
representations of the multiple aspects of identity. For example, they can be programmed with narrative behaviors to be used by others in a community. Zora's framework supports young people to learn by becoming designers. The idea of learning though design has been explored by educational technology projects addressing mostly science education (e.g. Kolodner et al, 1998; Resnick et al, 2000). However, this design-based approach has hardly been explored by humanistic education, which has favored engaging learners in introspection, reflection and discussion about issues of identity and values. Zora takes the best of both worlds offering opportunities for learners to introspect, reflect and discuss as well as by providing tools for them to become designers. Instead of designing a scientific instrument or an investigation that naturally leads to discussion about science, learners designed a complex representation of self and community, which led to discussions about issues of identity and values. For example, as shown in section 6.2, participants shared their differing points of view about death penalty, and then debated about the punishment they would implement in their virtual city.

\section{Identity construction environments engage in storytelling and elicit narratives}

about the self. In Zora, this was implemented by endowing every object in the virtual city with narrative attributes. The use of both objects and narratives in an integrated way, supported the expression of a sense of self in a deep and tangible way; as Pablo stated when he said that by looking at the objects in his room people could see who he is. The use of storytelling helped kids to think about the personal and moral values associated with the self. It supported children's exploration of values in a concrete way, by highlighting the object's relationship to identity. For example, when Elisa 
The Journal of the Learning Sciences. Vol 10 N 4. NJ: Lawrence Erlbaum. Pp 365-415

took a picture of her school yearbook and associated it with a personal story and the value "community", she explored not only the abstract concept of "community", but also how it relates to her through her school experience embodied by her yearbook.

\section{Identity construction environments support the creation and participation in a}

community. In the experience presented in this paper, workshop participants created a safe participatory micro-community and explored issues of identity and values. Zora supported the process of identifying and differentiating from others by engaging kids in the design of heroes and villains, as well as virtual temples representing shared interests or cultural roots. Zora provided a way for kids to engage in discussions about the social organization of the community. For example, after noticing the need for rules to regulate the activities in the virtual city, kids engaged in the creation of its laws. However, in Zora, participation in the community was not limited to engaging in meaningful discussions, such as the one about racism that kids had by the end of the workshop, but also included contributing through the design of objects and new places within the virtual city. For example, Eric was very shy to participate in the online conversation, but showed his interest in the topic, and his take on it, by creating the "Everyone's temple", a place for multicultural understanding.

\section{Open questions}

The learning stories highlight some of the strengths and successes of how the Zora identity construction environment supported learning about identity and values by engaging young people in the design of a graphical virtual city and its social organization. It is also instructive to look at the problems and difficulties encountered. Some of the problems were technical in nature, and are reasonably easy to fix. For 
example, the programming language to create conversations for objects and characters was difficult to learn and use, therefore none of the workshop participants was able to program an interesting interaction. This was fixed in later experiences with Zora. For example, young patients undergoing dialysis at Boston's Children's Hospital were able to program their characters to interact in thoughtful ways (Bers et al, 2001). Other technical problems were not so easy to fix such as the need for high bandwidth or a fast modem connection to avoid frequent computer crashes that disturb the engagement.

Other problems did not have technical fixes and instead require re-thinking or redesigning the nature of the learning experience. For example, since the Zora microcommunity was small, it was relatively easy for learners to reach consensus and engage in a participatory democracy. What will happen when scaling up? What mechanisms need to be put in place, when learners engage in a full-size virtual community and not only in a micro-community? What syllabus, if any, should facilitators follow when scaling up? What kind of assessment methods should be used to evaluate the learning experience when scaling up? The CSCL community has been struggling with these issues for a long time and research in this area should be useful when responding to these questions in future projects.

In the experience described in this paper, all the participants met face to face at least twice, and most of them were physically co-present when logged in. When difficult issues of socio-dynamics arose on-line, it was common for kids to go off-line to resolve them. What is the right balance between on-line and off -line activities? What kinds of 
The Journal of the Learning Sciences. Vol 10 N 4. NJ: Lawrence Erlbaum. Pp 365-415

issues require face to face interaction? Did the learners continue the kinds of conversations about controversial issues that they initiated on-line once they were face-to face? If this research were going to be done in a longitudinal way, the next step would be to see how these conversations engage kids in taking action not only in the virtual world but also in their communities at home, school, etc.

When the focus of the experience switches from a child-centered model of learning, such as the one described in this paper, to one where an adult has a more predominant role, new questions need to be answered. Should the adult indoctrinate learners about personal and moral values as the bag of virtues approach proposes (Bennett, 1993; Chazan, 1985)? Or should he or she be a neutral facilitator who does not interfere or reference personal or external values, but helps young people clarify their own values and engage in the valuation process such as "Values Clarification" argues for (Raths, Harmin \& Simon, 1978)? For example, should the facilitator seed the Zora virtual city with particularly controversial cases to foster debate? Should the teacher be an advocate of moral content and be a model of moral behavior or only a process facilitator? When and how a facilitator should intervene if participants decide to take an intolerant stance about a particular social, religious or racial group? What kind of knowledge about ethics and psychology and what counseling skills should he or she have? What design features should be put in place to ensure that the experience would be constructive and would engage kids in sophisticated discussions about personal identity as well as civics? 
The Journal of the Learning Sciences. Vol 10 N 4. NJ: Lawrence Erlbaum. Pp 365-415

As with other design-based and project-based educational initiatives, the Zora experience raises significant logistical challenges, as well as making special demands on the available technological infrastructure. Is $3 \mathrm{D}$ really needed or is it possible to implement a 2D version of Zora requiring less computational resources? As said earlier, 3D mainly served engagement and immersion purposes. It was not used to address a content matter that can be better understood and learned in 3D, such as physics, where the possibility of seeing a process in three dimensions adds to the comprehension of the concept (Dede et al, 1999). For the content of identity and values, 2D pictures would have been sufficient. However, it is not clear if it would have been enough to engage children in a selfmotivated way for long periods of time. Most of the workshop participants said that they liked the 3D aspects of Zora because of the navigational challenges it poses as well as the esthetical resemblance to popular video games. Further research needs to be done to answer the question about the benefits of 3D for ICE's.

The topic of identity and values in education is controversial for a number of reasons. One has been that it is not easy to define what needs to be learned and how to evaluate the learning experience. A narrow definition of research questions and methods is hard to achieve, not to mention clear measures of success and failure. Hopefully this paper has served to show a range of fruitful possibilities and that this area of research should prove promising to future researchers, designers and educators.

This work is just a first step and many questions are still unanswered: will the young people that participated in this experience carry their explorations of identity and values 
The Journal of the Learning Sciences. Vol 10 N 4. NJ: Lawrence Erlbaum. Pp 365-415

into the rest of their lives? Will the learning transfer to other contexts? How does the online experience compare with face to face only workshops? These questions are hard to answer and will require a different methodological approach.

The goal of this experience was to explore new possibilities and not to present a wellformed body of research. The goal is to use the lessons learned from this experience to define a research agenda that will advance focused research questions and evaluation methods to make approaches that use technology to learn about identity and values scalable and sustainable.

\section{Final reflections}

In democratic and pluralistic societies like the US, the topic of identity and values has largely been ceded to conservatives. By allowing this monopoly we diminish the debate about moral and character education and miss a unique opportunity to re-think their nature and importance in the light of new technologies in the field of the learning sciences. We live in a historical period that, comparatively with others, has three tremendous advantages to face the complexity of the challenge.

First, we have not yet "schoolified" values and identity education. By this I mean that the school mindset that has normalized our current views on curricula, education, such as the compartmentalization of subjects of study and the age segregation, has not spread yet to this domain. Therefore we still have the flexibility to debate and decide what content, pedagogy, tools and assessment methods can be used. The second advantage in facing the challenge of values and identity in education is the widespread pedagogical spirit of 
The Journal of the Learning Sciences. Vol 10 N 4. NJ: Lawrence Erlbaum. Pp 365-415

"learning by doing". This opens the possibility for constructionist methodologies that, by definition, avoid instruction and indoctrination. The third is the impact of new technologies. What computers were in the 80 's to influencing new ways of thinking and learning about mathematics and science, today they could be to values and identity. However, computers by themselves can`t produce changes. The philosophy behind the software matters, as does the context of its usage.

The research described in this paper shows the potential of computational tools for educational interventions that seek to foster self-awareness, personal cultivation and multicultural understanding. The hope is to provide a new way of conceiving moral and character education in the light of new technologies, as well as to invite designers of educational technology to join the effort and produce innovative tools purposefully designed to tackle these overlooked issues.

\section{Acknowledgements}

I am grateful to my advisor Seymour Papert and to members of my thesis committee Sherry Turkle, Mitchel Resnick, and Joe Gonzalez-Heydrich. Thanks to Linda Stone and Lili Cheng and the Microsoft Virtual Worlds research group. Also thanks to undergraduate research assistant Daniel Vlasic who was key in the implementation of Zora. I also would like to thank Mike Best for comments on an earlier draft, and to the reviewers for their thoughtful reviews. In particular, to Janet Kolodner, who encouraged me through all different stages of this paper and gave me wonderful feedback that helped me present my work in a better way. Finally, many thanks to Josh Bers for correcting the English in this paper and editing its many different versions. 
The Journal of the Learning Sciences. Vol 10 N 4. NJ: Lawrence Erlbaum. Pp 365-415

\section{References}

Barnes, M. (1996). The Healing Path with Children: an Exploration for Parents and Professionals. NY: Viktoria, Fermoyle \& Berrigan.

Barron, B., Schwartz, D., Vye N., Moore A., Petrosino A., Zech, L., Bransford J. \& The Cognition and Technlogy Group at Vanderbilt (1998). "Doing with understanding: Lessons from research on problem- and project-based learning". The Journal of the Learning Sciences 7 (3\&4), 271-310.

Bennett, W.J. (1993). The Book of Virtues: A Treasury of Great Moral Stories. NY: Simon \& Schuster.

Bers,M., Gonzalez-Heydrich,G. \& DeMaso, D.(2001). Identity Construction Environments: Supporting a Virtual Therapeutic Community of Pediatric Patients undergoing Dialysis. In Proceedings of Computer Human Interaction (CHI '01). Seattle, WA, USA. March 31-April 4, 2000. ACM

Bers, M. \& Cassell, J. (1998). Interactive storytelling systems for children: using technology to explore language and identity. Journal of Interactive Learning Research, volume 9 (2), 603-609.

Bers, M. (1998). A constructionist approach to values through on-line narrative tools. In Proceedings of International Conference for the Learning Sciences, (ICLS' 98), AACE, 49-55.

Bers, M. (1999). Zora: a Graphical Multi-user Environment to Share Stories about the Self. In Proceedings of Computer Support for Collaborative Learning (CSCL'99), 33-40.

Bers, M. \& Urrea, C. (2000). Technological Prayers: Parents and Children Working with Robotics and Values. In A.Druin \& J. Hendler (Eds.) Robots for Kids: Exploring New Technologies for Learning Experiences. Morgan Kaufmann, pp. 194-217.

Bisaillon, D. (1989). "Logo Computer Culture and Children's Development: The Influence of Socio-Moral Atmosphere". Unpublished doctoral dissertation. Harvard University, Cambridge.

Blasi, A. (1983). Moral Cognition and Moral Action: A Theoretical Perspective. Developmental Review, 3, pp 178-210.

Blasi, A. (1984). Moral Identity: Its role in Moral Functioning. In W Kurtines \& J. Gewirtz (Eds.) Morality, Moral Behavior and moral development. NY:Wiley \& Sons. 
The Journal of the Learning Sciences. Vol 10 N 4. NJ: Lawrence Erlbaum. Pp 365-415

Bobrow, D., O’Day, V., Saraswat, V., Hughes, B. \& Walters, J. (1995). “Building intentional networked learning communities". Presentation to the American Anthropological Association, Washington, DC.

Brosterman, N. (1997). Inventing Kindergarten. New York: Harry N. Adams Inc.

Bruckman, A. (1994). MOOSE Crossing: Construction, Community and Learning in a Networked Virtual World for Kids. Unpublished doctoral dissertation. Massachusetts Institute of Technology, Cambridge.

Bruckman, A. (1998). Community Support for Constructionist Learning. Journal CSCW 7:47-86.

Calvino, I. (1972). Invisible Cities. NY: Harcourt Brace Jovanovich.

Cavalier, R. (1996). "A right to die? The Dax Cowart Case" Published by Routledge, CD-ROM produced by the Center for the Advancement of Applied Ethics at Carnegie Mellon University.

Cavalier, R. (1998). "The issue of Abortion in America" Published by Routledge, CDROM produced by the Center for the Advancement of Applied Ethics at Carnegie Mellon University.

Chazan, B. (1980). Jewish Education and Moral Development. In (B. Munsey Ed.) Moral Development, Moral Education and Kohlberg. Religious Education Press, Birmingham, Alabama.

Chazan, B. (1985) Contemporary Approaches to Moral Education: Analyzing Alternative Theories. NY: Teachers College Press.

Coles, R. (1986). The Moral Life of Children. Boston: Atlantic Monthly Press.

Coles, R (1989). The Call of Stories: Teaching and the Moral Imagination. Boston: Houghton Mifflin.

Csikszentmihalyi, M. \& Rocheberg-Halton (1981) The Meaning of Things. Cambridge University Press.

De Bonte, A. (1998) Pet Park: a graphical constructionist community. MS Thesis. Massachusetts Institute of Technology, Cambridge. 
The Journal of the Learning Sciences. Vol 10 N 4. NJ: Lawrence Erlbaum. Pp 365-415

Dede, C., Salzman, M., Loftin, B. \& Sprague, D. (1999). Multisensory Immersion as a Modeling Environment for Learning Complex Scientific Concepts. In W. Feurzeig and N. Roberts, (Eds.), Computer modeling and simulation in science education, pp.282-319. New York: Springer-Verlag.

Donath, J.(1996). Inhabiting the Virtual City: The Design of Social Environments for Electronic Communities. Unpublished doctoral dissertation. Massachusetts Institute of Technology, Cambridge.

Edelson, D.C., Gordin, D.N., \& Pea, R.D. (1999). Addressing the challenges of inquirybased learning through technology and curriculum design. The Journal of the Learning Sciences, 8(3/4).

Erikson, E. H. (1950). Childhood and Society. NY: Norton and company.

Erikson, E. H. (1968). Identity: Youth and Crisis. NY: Norton and company.

Evard, M. (1996). A Community of Designers: Learning through Exchanging Questions and Answers. In Y. Kafai and M. Resnick (Eds.), Constructionism in Practice:

Rethinking the Roles of Technology in Learning. Hillsdale, NJ: Lawrence Erlbaum Associates.

Falbel, A. (1989). Friskolen 70: An Ethnographically Informed Inquiry into the Social Context of Learning. Unpublished doctoral dissertation, Massachusetts Institute of Technology, Cambridge.

Fowler, J. (1981). Stages of Faith: The Psychology of Human Development and the Quest for Meaning. SF: Harper.

Gardner, H. (1983). Frames of Mind: the Theory of Multiple Intelligences. NY : Basic Books

Geertz, C. (1973). The interpretation of cultures. New York, Basic Books.

Gilligan, C. (1982). In a Different Voice. Psychological Theory and Women's Development. Harvard University Press.

Gonzalez, J. (1995). Autotopographies. In Brahm Jr. \& M. Driscoll (Eds.) Prosthetic Territories. Politics and Hypertechnologies. SF: Westview Press.

Hickey, J. \& Scharf. (1980). Toward a Just Correctional System: Experiments in Implementing Democracy in Prisons. Jossey-Bass Publishers.

Herring, S. (1996). Computer-Mediated Communication. Amsterdam: John Benjamins. 
Hooper, P. (1993). They Have Their Own Thoughts: A story of Constructionist Learning in an Alternative African-Centered Community School. In Constructionism in practice. Kafai,Y. \& Resnick, M. (Eds.) Hillsdale NJ: Lawrence Erlbaum Associates.

Johnson, M. (1993). Moral imagination. Implications of cognitive science for ethics. University of Chicago Press.

Kohlberg, L. (1976). Moral stages and moralization: the cognitive-developmental approach. In T. Lickona (Ed.) Moral Development and Behavior. NY: Holt, Reinehart \& Winston.

Kohlberg, L. (1985). The just community approach to moral education in theory and in practice. In M. Berkowitz \& F Oser (Eds) Moral education: Theory and application. Hillsdale, NJ: Lawrence Erlbaum Associates

Kolodner, J., Crismond, C., Gray, J., Holbrook, J., \& Puntambekar, S. (1998). Learning by Design from Theory to Practice. Proceedings of the International Conference of the Learning Sciences (Atlanta, Dec. 1998). Charlottesville, VA: AACE.

Kollock, P. \& Smith, M. (1998). Communities in Cyberspace. Routledge

Kollock, P. \& Smith, M. (1996). Managing the virtual commons: cooperation and conflict in computer communities. In S. Herring (Ed.) Computer-Mediated Communication. Amsterdam: John Benjamins.

Lipman, M. (1988). Philosophy Goes to School. Philadelphia: Temple University Press

Morningstar, C. \& Farmer, R. (1990). The lessons of Lucasfilm's Habitat. In M. Benedikt (Ed.) Cyberspace: First Steps. Cambridge MA: MIT Press.

Norman, D. (1988). The Design of Everyday Things. NY: Doubleday

Okin,S. \& Reich, R. (1999). Families and Schools as Compensating Agents in Moral Development for a Multicultural Society. Journal of Moral Education. Volume 28 Number3, September 1999.

Pea, R., Edelson, D., \& Gomez, L. (1994). "The CoVis Collaboratory: High school science learning supported by a broadband educational network with scientific visualization, videoconferencing, and collaborative computing". Presented at the Annual Meeting of the American Educational Research Association, New Orleans, LA.

Papert S. (1980). Mindstorms: Children, Computers and Powerful Ideas. New York: Basic Books. 
The Journal of the Learning Sciences. Vol 10 N 4. NJ: Lawrence Erlbaum. Pp 365-415

Papert, S. (1987). The value of logic and the logic of values. In B. Inhelder, D. de Caprona, A. Cornu-Wells (Eds.) Piaget Today. NJ: Lawrence Erlbaum.

Piaget, J. (1965). The Moral Judgment of the Child. NY: Free Press.

Pinkett, R. D. (2000). "Bridging the Digital Divide: Sociocultural Constructionism and an Asset-Based Approach to Community Technology and Community Building". Paper presented at the 81st annual meeting of the American Educational Research Association (AERA), New Orleans, LA, pp. 24-28.

Raths, L.; Harmin, M. \& Simon, S. (1978). Values and Teaching. Columbus, OH: Merrill.

Reed, D. (1997). Following Kohlberg: Liberalism and the Practice of Democratic Community. University of Notre Dame Press. NotreDame: Indiana.

Resnick, M., Bruckman, A., \& Martin, F. (1996). Pianos Not Stereos: Creating Computational Construction Kits. Interactions, vol. 3, no. 6 (September/October 1996).

Resnick, M., Berg, R. \& Eisenberg, M. (2000). Beyond Black Boxes: Bringing Transparency and Aesthetics Back to Scientific Investigation. The Journal of the Learning Sciences, vol. 9, no. 1, pp. 7-30.

Rheingold, H. (1993). The Virtual Community: Homesteading on the Electronic Frontier. Reading, MA: Addison-Wesley Pub. Co.

Rosen, S. (1982). My voice will go with you: The teaching tales of Milton H. Erickson. NY: Norton.

Schank, R. (1994). Engines for Education. Institute for the Learning Sciences.

Selman, R. (1980). The growth of Interpersonal Understanding. NY: Academic Press.

Songer, N. (1996). Exploring Learning Opportunities in Coordinated Network-Enhanced Classrooms: A case of kids as global scientists. The Journal of the Learning Sciences. 5(4), 297-327.

Shaw, A. (1994). "Social Constructionism and the Inner City: Designing Environments for Social Development and Urban Renewal". Unpublished doctoral dissertation. Massachusetts Institute of Technology, Cambridge.

Tappan, M. \& Brown, L. (1989) Stories Told and Lessons Learned: Toward a Narrative Approach to Moral Development and Moral Education. Harvard Educational Review 59:2, 182-205.

Turkle, S. (1984).The Second Self: Computers and the Human Spirit. NY: Basic Books. 
The Journal of the Learning Sciences. Vol 10 N 4. NJ: Lawrence Erlbaum. Pp 365-415

Turkle, S. (1995). Life on the screen: Identity in the Age of the Internet. NY: Simon \& Schuster.

Turkle, S. \& Papert, S. (1992). "Epistemological Pluralism and the Revaluation of the Concrete". Journal of Mathematical Behavior, vol. 11, no. 1.

Vellon, M. Marple, K. Mitchell, D. \& Drucker, S. (1995). "The Architecture of a Distributed Virtual Worlds System". Virtual Worlds Group. Microsoft Research.

White, M. \& Epston, D. (1980). Narrative means to therapeutic ends. NY: Norotn and Co.

Wigren, J. (1994). Narrative Completion in the Treatment of Trauma, Psychotherapy, vol.31, no.3. 